\title{
Identification of an adult stem/progenitor cell-like population in the human thyroid
}

\author{
Alessandra Fierabracci, Maria Ausiliatrice Puglisi, Laura Giuliani, Stefano Mattarocci ${ }^{1}$ \\ and Marco Gallinella-Muzi ${ }^{2}$ \\ Autoimmunity and Organ Regeneration Laboratory, Ospedale Pediatrico Bambino Gesù Scientific Institute, Children's Hospital Bambino Gesù, Piazza S. \\ Onofrio 4, 00165 Rome, Italy \\ ${ }^{1}$ Istituto di Neurobiologia e Medicina Molecolare-CNR, Via Fosso del Fiorano, 64, 00143 Rome, Italy \\ ${ }^{2}$ Department of Surgery, Tor Vergata University, Viale Oxford 81, 00133 Rome, Italy \\ (Correspondence should be addressed to A Fierabracci; Email: fierabracci@med.uniroma2.it; alefierabracci@hotmail.it)
}

\begin{abstract}
There is evidence that tissue-specific stem cells reside in certain adult tissues. Their specific properties remain elusive, because they are rare and heterogeneous in parent tissues; furthermore, technical difficulties have been encountered in the identification and characterization of their progeny. The aim of this study was to isolate stem/progenitor cells from the human thyroid. We devised a method based on the enzymatic digestion of fresh surgical thyroid specimens, followed by culture of cells in the presence of epidermal growth factor and basic fibroblast growth factor. We also used markers that identify and characterize these cells. Spheroids with selfreplicative potential were obtained from all thyroid specimens. The isolated population contained a subset of CD34+
\end{abstract}

CD45 - cells and it was able, in differentiation conditions, to generate follicles with thyroid hormonal production. In support of the plasticity concept, we obtained evidence that, when most freshly isolated spheroids were co-cultured with a neuroblastoma cell line, they produced progeny expressing the neuronal marker $\beta$-tubulin III. Spheroids were also able to undergo adipogenic differentiation when cultured in adipogenic medium. We conclude that a predominant functional type of stem/progenitor cell exists within the thyroid, with an intrinsic ability to generate thyroidal cells and the potential to produce non-thyroidal cells.

Journal of Endocrinology (2008) 198, 471-487

\section{Introduction}

Stem cells are clonogenic, self-renewing and able to differentiate into multiple lineages (Weissman 2000, Blau et al. 2001, Korbling \& Estrov 2003). Stem cells in compact organs are restricted in their differentiation and regenerative potential to the tissue of origin, instead, embryonic stem cells are pluripotent. According to a new view, stem cells present in adult organs could first reside in them but they may contribute to its formation, when moved to another organ (Wagers \& Weissman 2004). Therefore, in principle, stem cells resident in adult organs could be used as an alternative to embryonic stem cells in regenerative medicine (Uchida et al. 2000, Blau et al. 2001, Korbling \& Estrov 2003, Nunes et al. 2003).

Haematopoietic and neural stem cells, also termed neurospheres, seem to be the better characterized adult stem cells (Goodell et al. 1996, Shih et al. 2001, Gritti et al. 2002, Galli et al. 2003). Cells isolated from the embryonic, neonatal and adult rodent central nervous system are grown in response to epidermal growth factor (EGF) and basic fibroblast growth factor (bFGF; Gritti et al. 1996), and are able to differentiate into neurons and glia. They can also be isolated from embryonic and adult human brain (Nunes et al. 2003). Neurospheres are aggregates of clonogenic cells, which contain a heterogeneous mix of both multipotent stem cells and more restricted progenitor populations. They undergo extensive in vitro expansion that seems applicable for the regeneration in various disorders of the central nervous system (Horner \& Gage 2000, Teng et al. 2002). Injection of adult neurospheres has also been shown to induce functional recovery in a mouse model of chronic multiple sclerosis (Pluchino et al. 2003). Subsequently, similar populations of spheroids have been isolated from other compact organs, such as human skeletal muscle (Alessandri et al. 2004), human and murine heart (Messina et al. 2004), human bladder (Fierabracci et al. 2007) and human exocrine pancreas (Puglisi et al. 2008).

The issue of isolating adult stem cells has not been fully addressed for the human thyroid (HT). The gland consists of several cell types that are derived from all three embryonic germ layers and is of fundamental importance in metabolic homeostasis, growth and development throughout the synthesis of thyroid hormones tri-iodothyronine $\left(\mathrm{T}_{3}\right)$ and thyroxine $\left(T_{4}\right.$; Braverman \& Utiger 1991). The thyroid follicular cells, which represent the most abundant cell 
population of the gland, are of endodermal origin. Thyroid hormones derive from the degradation of the large precursor thyroglobulin $(\mathrm{Tg})$, which is iodinated by the thyroid-specific enzyme thyroperoxidase (TPO). Three factors, i.e. Thyroid transcription factor 1 (TTF1), Thyroid transcription factor 2 (TTF2) and Paired box 8 (PAX8) have been implicated in the control of transcription of the thyroid differentiation molecules, such as TPO, Tg, thyrotrophin receptor (TSHR) and $\mathrm{Na}^{+} / \mathrm{I}^{-}$symporter (NIS; Damante et al. 2001), intervening in the complex machinery of thyroid hormones synthesis. The thyroid tissue also consists of capillary endothelial cells, fibroblasts and a few calcitonin- and somatostatin-producing parafollicular cells (C cells). The latter cell population is involved in calcium homeostasis and exerts a paracrine activity on thyrocytes (Fierabracci et al. 1993).

Evidence for a stem cell origin has been provided for solid cell nests of the thyroid (Reis-Filho et al. 2003) and, in a mouse model, experiments have been conducted in which embryonic stem cells became committed to differentiate into thyrocyte-like cells in vitro (Lin et al. 2003). Evidence has been provided for a microchimerism of presumed fetal origin in thyroid specimens from the mothers (Srivatsa et al. 2001). Recently, adult stem cells were obtained from human goitres. They were separated by flow cytometry from differentiated thyrocytes and endodermal markers-positive cells as a side population due to their ability to express ATP-binding cassette transporter subfamily G (ABGG2) transporter (Thomas et al. 2006, Lan et al. 2007, Lin 2007; Rev in Thomas et al. 2008). Co-culture with thyrocytes resulted in the formation of non-adherent three-dimensional (3D) spheres able to differentiate TSH dependently into thyroid cells. Side population cells were also isolated in the mouse thyroid (Hoshi et al. 2007; Rev in Thomas et al. 2008). In our experiments, we have used the HT and, in particular, normal thyroid specimens as a model of investigation and employed a different method to isolate stem/progenitor cells from this organ, for their morphological-functional characterization and their differentiation.

\section{Materials and Methods}

\section{Primary, secondary and higher-passaged spheroid cultures}

Tissue $\left(1 \mathrm{~cm}^{3}\right.$ blocks) was obtained from 23 fresh surgical thyroid specimens. Normal specimens were dissected from the perinodular tissue of glands obtained from 13 patients affected by thyroid adenoma (HT4, HT9, HT20, HT22, HT24, HT25, HT27, НT31, НT56, НT62, НT63, НT66 and HT72). Normal tissue was also dissected from six thyroids (HT14, HT49, HT50, HT51, HT52 and HT53) at the time of laryngectomy for carcinoma of the larynx. Glands were also obtained from four patients affected by Graves' disease (HT18, HT21, HT23 and HT69).

The blocks from all the thyroids were enzymatically digested in collagenase type IV (Gibco; $2 \mathrm{mg} / \mathrm{ml}$ in Roswell Park Memorial Institute Medium (RPMI); Fierabracci et al.
2001); supernatants, containing the great majority of differentiated cells (e.g. thyrocytes, endothelial cells), were discarded, while thyroid fragments, residual to digestion, were collected, plated and cultured in the 'spheroid medium' in $100 \mathrm{~mm}$ polystyrene Petri culture dishes (BD Falcon, Becton Dickinson (BD), Franklin Lakes, NJ, USA). This 'spheroid medium' consisted of a 1:1 mixture of Dulbecco's Modified Eagle's Medium (DMEM) (high glucose content; Gibco) and F12 nutrient (1:1 (v/v), Sigma Chemical C), including glucose $(25 \mathrm{mM})$, sodium bicarbonate $(3 \mathrm{mM})$, L-glutamine $(2 \mathrm{mM})$, penicillin $50 \mathrm{U} / 1$ and streptomycin $(50 \mu \mathrm{g} / \mathrm{ml})$. In place of serum, a defined hormone and salt mixture was added to the culture medium; this mixture, first used for generating neurospheres (Gritti et al. 1996), consisted of insulin (25 $\mu \mathrm{g}$ / $\mathrm{ml}$; Sigma), transferrin $(100 \mu \mathrm{g} / \mathrm{ml}$; Sigma $)$, progesterone (30 $\mu \mathrm{M}$; Sigma), putrescine $(60 \mu \mathrm{M}$; Sigma) and sodium selenite (30 nM; Sigma). $\beta$-mercaptoethanol $(0 \cdot 1 \mathrm{mM}$; Sigma) and the human recombinant growth factors EGF and bFGF (20 ng/ml; Sigma) were also added. The addition of the latter growth factors was critical for the generation of spheroids and for their subsequent expansion in culture (vide infra). Primary aggregates of cells with a 'spheroid-like' structure, similar to neurospheres, were harvested after 7-10 days. They were centrifuged at $453 \mathrm{~g}$ for $5 \mathrm{~min}$ first, mechanically dissociated into single cells and then resuspended in fresh medium for generating secondary cultures. This procedure was repeated for each generated line every 7 days for an average time of 2 months.

An alternative approach employed culture conditions similar to those described for the generation and expansion of cardiospheres (Messina et al. 2004). In this procedure, tissue fragments, residual to digestion, were washed and cultured at $37^{\circ} \mathrm{C}$ and $5 \% \mathrm{CO}_{2}$ in polystyrene tissue culture dishes (BD Falcon) in a complete explant medium; this consists of Iscove's modified Dulbecco's medium (Gibco) supplemented with $10 \%$ fetal bovine serum (FBS, Hyclone, South Logan, UT, USA), L-glutamine (2 mM), penicillin (50 U/1), streptomycin $(50 \mu \mathrm{g} / \mathrm{ml})$ and $\beta$-mercaptoethanol $(0 \cdot 1 \mathrm{mM})$. After $\sim 2$ weeks, a layer of fibroblast-like cells was generated from adherent explants. Supernatant cells were recovered, washed and seeded at $0.5 \times 10^{4}$ cells $/ \mathrm{ml}$ in six-well plates coated with polylysine (Sigma) and cultured in a growing medium consisting of DMEM and F-12 (1:1) supplemented with $\beta$-mercaptoethanol, EGF, bFGF, antibiotics and L-glutamine.

Experiments were also conducted plating in parallel the same number of spheroids of the HT66 line, harvested after 7-10 days from their generation, in 24-well tissue culture plates (BD Falcon) and cultured separately in three different culture conditions. One set of spheroids was cultured in 'spheroid culture medium' supplemented with EGF and bFGF; another set of spheroids was cultured in 'spheroid culture medium' supplemented with EGF alone and the last set of spheroids was cultured in 'spheroid culture medium' supplemented with bFGF alone. This experiment attempted to compare the proliferation efficiency of the different combinations of growth factors. Cell number obtained in 
the different culture conditions was determined in triplicate using a Coulter counter after 10 days (time 1) and additional 2 weeks (time 2) of culture.

\section{Proliferation assay of spheroids derived from HT cell lines (HT14 and HT56)}

In order to assess the proliferation capacity, the spheroids of the HT14 and HT56 lines were employed. Serial halving of the fluorescence intensity of the vital dye carboxyfluorescein diacetate succimidyl ester (CFDE, Invitrogen Corporation; Lyons 1999) was measured by flow cytometry. Briefly, the spheroids of the two lines were harvested 1 month after they had been generated, centrifuged at $453 \mathrm{~g}$ for $5 \mathrm{~min}$ and resuspended in $2.5 \mathrm{ml}$ of $0.1 \%(\mathrm{w} / \mathrm{v})$ BSA/PBS solution at room temperature. Spheroids were again centrifuged, the pellet was dissociated into single cells by pipetting, resuspended and incubated at $37^{\circ} \mathrm{C}$ for $20 \mathrm{~min}$ in $500 \mu \mathrm{l}$ of $0.5 \%$ (w/v) BSA/PBS solution containing $5 \mu \mathrm{M}$ CFDE. Spheroid cells were then washed in $0 \cdot 5 \%(\mathrm{w} / \mathrm{v}) \mathrm{BSA} / \mathrm{PBS}$ solution and plated in the 'spheroid culture medium'. In parallel and as control, cells of the same lines were not stained with CFDE, but only cultured in the spheroid medium. In order to quantify the intensity of the CFDE labelling, an aliquot of stained cells and of control cells was analysed by flow cytometry, immediately after an staining (time 1) and after an additional 7 (time 2), 14 (time 3) and 21 days (time 4).

\section{Determination of cumulative population doubling}

(PD) Cumulative number of PDs attained over the course of the in vitro culture life span was determined according to standard protocols (http://www.worthington-biochem. com). At the time of cell isolation from plated tissue fragments, cell population was considered to be at one PD. The number of PDs at every passage thereafter was calculated as $\log 10(N / \mathrm{No}) \times 3 \cdot 33$, where $N$ is the number of cells in the growth plate at the end of a period of growth and No is the number of cells plated in the growth plate. Cultures were deemed to have reached the end of their in vitro life span when lack of proliferation was assessed by serial halving of the fluorescence intensity (vide supra), therefore in vitro senescence occurred. Cell number was determined in triplicate using a Coulter counter.

\section{Human telomerase (hTERT) gene expression and telomere length analysis}

RNA amplification kit SYBR Green I on Light Cycler instrument (Roche) was used for the detection of hTERT expression in a real-time RT-PCR. Total RNA samples from HT39, HT62, HT69 spheroid lines, thyroid tissue and HeLa cells, as a positive control, were amplified. Primer sequences for hTERT (forward: 5'-ACGCGAAAACCTTCCTCAG-3'; reverse: 5'-TGTCTTCCGCAAGTTCACC $-3^{\prime}$ ) were obtained from the ProbeFinder assay design software (available at www.universalprobelibrary.com).
The amplification programme consisted of 1 cycle of denaturation at $95^{\circ} \mathrm{C}$ for $30 \mathrm{~s}$ followed by 45 cycles of denaturation step at $95^{\circ} \mathrm{C}$ for $0 \mathrm{~s}$, annealing at $60^{\circ} \mathrm{C}$ for $10 \mathrm{~s}$ and extension at $72{ }^{\circ} \mathrm{C}$ for $10 \mathrm{~s}, 1$ cycle of cooling at $40^{\circ} \mathrm{C}$ for 30 s. Quantitative RT-PCR for GAPDH (forward: $5^{\prime}-$ TCCCTGAGCTGAACGGGAAG-3'; reverse: 5'-GGAGGAGTGGGTGTCGCTGT $-3^{\prime}$ ) was carried out on each sample as an internal control for equivalence of template. Melting curve and 2\% agarose gel electrophoresis analysis was also done to verify specificity and size of the amplified DNA fragments.

Telomere length was determined by telomere restriction fragment (TRF) Southern blot analysis. High molecular weight DNA was isolated by 'salting out' method and aliquots of $1 \mu \mathrm{g}$ were double digested overnight with $5 \mathrm{U}$ RsaI and Hinfl. Digested DNA fragments were separated on $0.7 \%$ agarose gel and transferred to nylon membrane filters (Hybond $\mathrm{N}+$ ). The filters were pre-hybridized and hybridized to $\gamma$-P32 kinase (TTAGGG) 3 probe in Quick Hybridization solution (Stratagene) following standard procedures. The median TRF lengths were calculated using the TELORUN program (available at http://www4. utsouthwestern.edu/cellbio/shay-wright/research/sw_lab_methods.htm).

\section{Clonogenesis}

Spheroids of the HT14 and HT56 lines were recovered from culture dishes after 10 days from its generation, partially dissociated by pipetting, eventually stained with CFDE (as mentioned above), plated as single cells by limiting dilution on 96-well round bottomed tissue culture dishes (Corning Incorporated, Costar, Corning, NY, USA) and cultured in 'spheroid culture medium'. Every week, $20 \mu \mathrm{l}$ fresh medium were added to each well. The generation of spheroids from single cells was monitored in the single wells every week up to 45 days.

\section{Immunophenotyping}

Spheroids of individual HT lines (HT14, HT18, HT20, HT21, HT22, HT23, HT25, HT26, HT49, HT50, HT56, HT62, HT63 and HT66) were collected between 1 and 2 months after being generated and characterized by immunocytochemistry and fluoresence-activated cell sorting (FACS) for surface and intra-cytoplasmic markers of expression at the single-cell level.

Immunocytochemistry Spheroids (HT14, HT18, HT20, HT21, HT22, HT23 and HT49) were attached to glass coverslips or cytospun on slides and stained by standard indirect immunofluorescence (IFL). In brief, cells were fixed for $3 \mathrm{~min}$ with methanol/acetone mixture (1:1) and rinsed three times with Hanks' balanced salt solution (HBSS, $\mathrm{pH}$ $7 \cdot 4$; Gibco). In order to reveal relevant thyroid differentiation markers, the following antisera were employed: for 
intra-cytoplasmic markers, rabbit polyclonal anti- $\mathrm{Tg}(1: 1000$, Dako Corporation, Carpinteria, CA, USA), MoAb 47 antiTPO (1:10, a gift from Dr J Ruf, Université de la Méditerranée, Marseille Cédex, France; Ruf et al. 1989) and for surface marker, MoAb 2C11 anti-human TSH-R (1:10, Serotec, Raleigh, NC, USA; Johnstone et al. 1994). Staining with the latter $\mathrm{MoAb} 2 \mathrm{C} 11$ required final fixation in ethanol/acetone mixture (95:5) for $1 \mathrm{~min}$. Antibodies, diluted in HBSS, $1 \%(\mathrm{w} / \mathrm{v})$ BSA, were individually incubated for $1 \mathrm{~h}$ at room temperature on the coverslips or cytospun slides, which were then washed three times ( 5 min each) in HBSS, $1 \%(\mathrm{w} / \mathrm{v})$ BSA and stained for $1 \mathrm{~h}$ at room temperature with the following second antibodies: goat anti-rabbit IgG (whole molecule) fluorescein isothiocyanate (FITC) conjugated (1:80, Sigma) or goat anti-mouse IgG FITC conjugated (1:50, Sigma). After that, they were rinsed three times in HBSS, 1\% (w/v) BSA and one time in distilled water and finally mounted in Dako fluorescent mounting medium. The percentage of fluorescent stained spheroids per microscopic fields was assessed, by two independent observers, at $100 \times$ magnification.

FACS analysis Spheroids (HT14, HT18, HT20, HT21, HT22, HT23, HT25, HT26, HT49, НT50, НT56, НT62, HT63 and HT66) were collected from culture dishes, centrifuged at $394 \boldsymbol{g}$ for $5 \mathrm{~min}$ and resuspended in FACS buffer (calcium/magnesium free Dulbecco's PBS $1 \times$ (Euroclone), $3 \%$ (v/v) FBS, $0 \cdot 1 \%$ sodium azide (Sigma)). Single-cell suspensions of $\sim 1 \times 10^{6}$ elements were stained with directly conjugated MoAbs (1:10 dilution) directed against the following common human surface stem cell markers: CD34 (phycoerythrin (PE) conjugated; BD Pharmingen, San Diego, CA, USA), CD45 FITC conjugated (BD Pharmingen) and CD117 (c-kit) (cychrome conjugated; BD Pharmingen). Staining was also performed with the following directly conjugated MoAbs (1:5 dilution) directed against 'stroma cell markers': Stro-1 (FITC conjugated; Santa Cruz Biotechnologies, Santa Cruz, CA, USA), CD44 (FITC conjugated; BD Pharmingen), CD105 (SH2) (FITC conjugated; Biolegend, San Diego, CA, USA) and CD73 (SH3) (PE conjugated; Becton Dickinson (BD) Pharmingen).

The following unconjugated MoAbs were also used: anti-human haematopoietic stem cell markers AC133/1 and AC133/2 (1:25; Miltenyi Biotech, Auburn, CA, USA; Yu et al. 2002, Fargeas et al. 2003), anti-human endothelial cell markers CD144 (catherin 5; 1:25; BD Pharmingen), anti-human CD31 (PECAM; 1:25; BD Pharmingen) and anti-human TSH-R 2C11 and 4C1 clones (1:10; Serotec).

For intra-cytoplasmic staining, cells were first fixed in FACS buffer, 1\% (v/v) paraformaldehyde solution for $15 \mathrm{~min}$ at room temperature, then washed by centrifugation at $453 \mathrm{~g}$ for $5 \mathrm{~min}$ and permeabilized in FACS buffer, $0 \cdot 01 \%(\mathrm{w} / \mathrm{v})$ saponine. The subsequent intra-cytoplasmic staining was performed with MoAb 47 anti-TPO (1:100, provided by Dr J Ruf, Marseille, France), rabbit anti-human calcitonin (1:10, Novocastra Laboratories, Newcastle Upon Tyne, UK), rabbit anti-human $\operatorname{Tg}(1: 1000$, Dako), MoAb anti-human Tg (1:100, Sigma), rabbit anti-human somatostatin (1:10, Dako), MoAb anti-human nestin (1:10, Chemicon International, Inc., Temecula, CA, USA) and MoAb anti-human $\beta$-tubulin isotype III (1:10, Sigma). Surface and intra-cytoplasmic staining was also performed with MoAb anti-human NIS (1:10, a gift from Dr S Costagliola, IRIBHM, Universite Libre de Bruxelles, Bruxelles, Belgium; Pohlenz et al. 2000). After incubation with the unconjugated polyclonal or MoAbs, cell preparations were stained with second antibodies goat antimouse IgG, Fc $\gamma$-fragment specific, FITC conjugated (1:10, Jackson ImmunoResearch, Suffolk, UK) and goat anti-rabbit IgG FITC conjugated (1:80, Sigma).

Reverse transcription and PCR (RT-PCR) for the expression of nestin, pluripotency markers Oct-4 and Nanog

Total cellular RNA was extracted from cells grown in cultures (HT14, HT18, HT20, HT21, HT22, HT23, HT39, HT49, HT50, HT51, HT56, HT62, HT63, HT66, HT69 and HT72), according to standard protocols (Rneasy Qiagen mini kit) and cDNA prepared according to SuperScript First-Strand synthesis system for RT-PCR (Invitrogen). PCR primers for human nestin were tested according to published protocols (Zulewski et al. 2001). Specific primers for Oct-4 were as follows: forward: $5^{\prime}$-GAAGGATGTGGTCCGAGTGT- $3^{\prime}$ and reverse: $5^{\prime}$-CAAAAACCCTGGCACAAACT- $3^{\prime}$ and identified a product of $356 \mathrm{bp}$. Specific primers for Nanog were forward 5'-TGCAAATGTCTTCTGCTGCTGAGAT-3', reverse $5^{\prime}$-GTTCAGGATGTTGGAGAGTTC- $3^{\prime}$ and identified a product of $\sim 286 \mathrm{bp}$. PCR conditions were: $3 \mathrm{~min}$ at $94{ }^{\circ} \mathrm{C}$, $30 \mathrm{~s}$ at $94{ }^{\circ} \mathrm{C}, 30 \mathrm{~s}$ at annealing temperature, $30 \mathrm{~s}$ at $72{ }^{\circ} \mathrm{C}$ for 40 cycles, followed by extension at $72^{\circ} \mathrm{C}$ for $10 \mathrm{~min}$.

\section{Morphological and functional studies}

Collagen gel culture of spheroids We adopted the 3D collagen gel culture system, previously successfully applied to differentiated thyrocytes (Curcio et al. 1994, Kusunoki et al. 2001, Toda et al. 2001, 2002, Kusunoki et al. 2002) to verify whether spheroids of five generated thyrosphere lines (HT22, HT23, HT49, HT56, HT62 and HT63) could be induced to a partial or full differentiation thyroidal phenotype. Approximately, three weeks after these lines were generated, thyrospheres were picked up from them, partially dissociated by pipetting and spun down at $453 \mathrm{~g}$ for $5 \mathrm{~min}$. By doing that, the 'spheroid medium', i.e. the growth factor-containing medium was removed. Approximately, $2 \times 10^{6}$ cells, partially dissociated from the thyrospheres, were resuspended in four different media in each well of multichamber slides (four wells, Falcon Labware BD Biosciences, Oxnard, CA, USA). One series of replicates consisted of one well of cells, i.e. the control thyrospheres, resuspended in a culture medium, composed of one volume of type 1 bovine collagen solution (Stem Cell Technologies, Inc., Vancouver, BC, Canada) and two volumes of 'spheroid medium'. The other three wells of 
cells, partially dissociated from the thyrospheres, were resuspended in a 'culture medium' composed of one volume of type 1 bovine collagen solution (Stem Cell Technologies, Inc.), but each one had added two volumes of a distinct 'differentiating medium'; the first of these differentiation media consisted of DMEM and F12 nutrient (1:1 v/v), additionally supplemented, in place of EGF, bFGF and $\beta$-mercaptoethanol, with 10\% (v/v) FBS (known to contain iodine), human recombinant $\alpha$-TSH $(0 \cdot 44 \mu \mathrm{g} / \mathrm{ml}$, Genzyme, Naarden, The Netherlands) and 8-Br-cAMP (1 nmol, Sigma); the second medium consisted of DMEM and F12 nutrient, supplemented with FBS and $\alpha$-TSH and the third medium consisted of DMEM and F12 nutrient supplemented only with FBS. Seven hundred and fifty microlitres of the four different collagen gel cell mixtures were placed in each well of multichamber slides.

The mixtures were immediately heated to $37^{\circ} \mathrm{C}$ to allow gel formation. The four wells of cells were cultured in the collagen gel, each supplemented with its own distinct medium, and for up to 4 weeks, they were maintained at $37^{\circ} \mathrm{C}$ in humid air, containing $5 \% \mathrm{CO}_{2}$. Medium $(200 \mu \mathrm{l})$ was collected from each of the four wells of cultures every week and replaced with the corresponding fresh medium (see $\mathrm{T}_{3}, \mathrm{~T}_{4}$ determination).

\section{Morphological observation and immunohisto- chemistry for cell identification and differentiation} The four wells of thyrospheres were seeded in collagen for 4 weeks. One series of replicates was fixed with $10 \%(\mathrm{v} / \mathrm{v})$ formalin, routinely processed and embedded in paraffin. Deparaffinized sections $(10 \mu \mathrm{m}$ thick) were stained with haematoxylin-eosin. The other series of replicates was fixed with methanol/acetone mixture and stained, by indirect IFL, with MoAb anti-Tg, anti-TPO and anti-TSH-R, as described above.

$T_{3}, T_{4}$, calcitonin and somatostatin determinations in culture supernatants Culture supernatants $(200 \mu \mathrm{l})$ from 'differentiating' and 'control' thyrospheres seeded in collagen were collected every week for 4 weeks and stored at $-20{ }^{\circ} \mathrm{C}$, until assayed for $\mathrm{T}_{3}$ and $\mathrm{T}_{4}$ levels (Cell Dyn, Abbott Laboratories). Fresh medium of the four distinct medium combinations was replaced each time. Individual batches of FBS (assayed neat or at $10 \%$ dilution) had only traces of $\mathrm{T}_{3}$ and $\mathrm{T}_{4}$. Culture supernatants were also assayed for calcitonin (IRMA, Scantibodies, Santee, CA, USA) and somatostatin (RIA, EuroDiagnostica, Malmö, Sweden). No $\mathrm{T}_{3}$ and $\mathrm{T}_{4}$ production was ever detectable in culture supernatants, when the same lines were cultured and expanded in the 'spheroid culture medium' even outside the 3D system in the standard culture dishes.

\section{Co-culture of thyroidal spheroids with a neuroblas- toma cell line We attempted to verify whether spheroids obtained from the thyroids could acquire the phenotypic characteristics of a neuronal lineage. For performing that, we initially co-cultured the spheroids with the neuroblastoma cell}

line LAN5 (De Tullio et al. 2000). Carboxyfluorescein diacetate dye (CFDA, Sigma; Lyons et al. 1999) was used to label the spheroidal cells of the HT56, HT63 and HT66 lines, as described (vide supra). This was done in order to monitor their cell division capacity and any morphological changes they might have undergone. CFDA pre-stained cells $\left(1 \times 10^{6}\right)$ were then added to the differentiated neuroblastoma cells (kindly supplied by Prof. C Dominici, La Sapienza University, Rome, Italy; De Tullio et al. 2000), at an initial ratio of 1:1 and cultured in $25 \mathrm{ml}$ vented culture flasks in the 'spheroid medium', supplemented, this time, with $10 \%(\mathrm{v} / \mathrm{v}) \mathrm{FBS}$, but deprived of EGF, bFGF and $\beta$-mercaptoethanol. In this system, spheroids were exposed to differentiating factors produced by neuroblastoma cells.

In this co-culture system, the neuroblastoma cells were growing in adherence, while CFDA-stained spheroids remained floating in the supernatant. After 3-8 days of co-culture, CFDA-positive spheroids were recovered from the supernatants and divided into two aliquots. The first aliquot was analysed by flow cytometry only for the intracytoplasmic expression of the neuronal marker $\beta$-tubulin III. In parallel experiments and as a control, the expression of $\beta$-tubulin III was also evaluated in spheroid cells of the HT56 line and in the neuroblastoma cell line (cultured in RPMI, supplemented with $10 \%(\mathrm{v} / \mathrm{v})$ FBS, L-glutamine $(2 \mathrm{mM})$, penicillin $(50 \mathrm{U} / \mathrm{l})$ and streptomycin $(50 \mu \mathrm{g} / \mathrm{ml}))$.

In order to examine the morphology of the CFDA-positive cells undergoing 'neuronal differentiation', the second aliquot of the recovered CFDA-positive spheroids was plated on chamber slides (eight wells (Falcon) pre-coated with polylysine; Sigma) for $1 \mathrm{~h}$ at $37^{\circ} \mathrm{C}$, cultured for an additional 2-3 days in serum-free 'spheroid medium', supplemented with human platelet-derived growth factor $(10 \mathrm{ng} / \mathrm{ml}$ PDGF-BB, R\&D system, Minneapolis, MN, USA), brain derivative nerve growth factor $(50 \mathrm{ng} / \mathrm{ml}$ BDNGF, Sigma) and retinoic acid ( $5 \mathrm{mM}$, Sigma). At the end of the additional culture period, the CFDA-stained spheroids were fixed with methanol/acetone mixture and stained by indirect IFL with antisera against relevant neural differentiation marker, i.e. MoAb anti-human $\beta$-tubulin isotype III (1:5, Sigma), MoAb anti-human neurofilaments (commercially pre-diluted, Dako), rabbit anti-human synaptophysin (commercially pre-diluted, Dako). Secondary antibodies were rhodamineconjugated goat anti-mouse $\operatorname{IgG}$ (1:50, Chemicon International) and rhodamine-conjugated goat anti-rabbit IgG (1:50, Chemicon International) respectively.

Mesenchymal differentiation of thyrospheres The 'plasticity' of thyrospheres and mesenchymal differentiation experiments were performed according to already described protocols (Zuk et al. 2002).

Adipogenic and osteogenic differentiation. Spheroids of the HT63 line were cultured in parallel in six-well tissue culture plates (BD Falcon, Becton Dickinson) in control 'spheroid culture medium' (i.e. containing EGF and bFGF), in adipogenic medium for $2-3$ weeks or in osteogenic medium 
(OM) for 5 weeks (Zuk et al. 2002). Spheroids were then cytospun on slides and assessed morphologically, histologically and histochemically with oil red $\mathrm{O}$ staining and ematossilin (as counterstain) to reveal adipogenic differentiation or with Von Kossa staining to reveal osteogenic differentiation respectively.

In vivo experiments to assess tumorigenicity To test in vivo tumorigenicity, two severe combined immunodeficient (SCID) mice, 6 weeks old, were injected both subcutaneously and intra-organ, i.e. testis or liver, with a suspension of spheroid cells recovered respectively from the HT22 and HT23 lines. Approximately, $1 \times 10^{6}$ viable cells were injected in $200 \mu \mathrm{PBS}$ solution. Mice were monitored for 2 months after the injection to assess eventual tumour development. At the end of the experimental procedure, mice underwent killing. The tissue surrounding the site of injection was excised from xenografted mice, frozen in liquid nitrogen and stored at $-80{ }^{\circ} \mathrm{C}$.

Histological examination. Thick sections $(10 \mu \mathrm{m})$ were cut from frozen blocks and stained by IFL with unconjugated L31 $\mathrm{MoAb}$ for $1 \mathrm{~h}$ at room temperature, specifically raised against human MHC class I (1:100 dilution, kindly provided by Dr P Giacomini, Regina Elena Institute, Rome). After washing in PBS, second antibody goat anti-mouse IgG, Fc $\gamma$-fragment specific, FITC conjugated (1:10, Jackson ImmunoResearch) was incubated for $30 \mathrm{~min}$ at room temperature.

\section{Results}

EGF- and bFGF-responsive neurosphere-like elements derived from normal and pathological human adult thyroids

The thyroid fragments, the products of the initial enzymatic digestion, were kept in culture for 7-10 days. During this time, the few residual differentiated cells (e.g. thyrocytes, endothelial cells) remained attached to the bottom of the culture dish; thyrocytes were progressively de-differentiating into fibroblast-like cells, confirming a phenomenon known to occur between 7 and 10 days from the start of primary thyrocyte cultures (Fierabracci et al. 2001). Meanwhile, small primary aggregates of cells appeared floating in the supernatant (Fig. 1A), started then to proliferate (Fig. 1B) and became increasingly more numerous (Fig. 1C). When individually observed, these cell aggregates appeared with a 'spheroid-like' structure similar to that described for neurospheres (Goodell et al. 1996, Shih et al. 2001, Gritti et al. 2002, Galli et al. 2003). The number of thyroid spheroids, now called 'thyrospheres', was $\sim 2 \times 10^{4} / \mathrm{ml}$.

At this time, the spheroids were harvested by centrifugation, mechanically dissociated into single cells, resuspended in fresh medium and finally replated in new tissue culture plates. During the next 7 days, cells, while in culture, were monitored and, from single cells, they reformed 'spheroids'. At this point, approximately a threefold increase in the number of spheroids

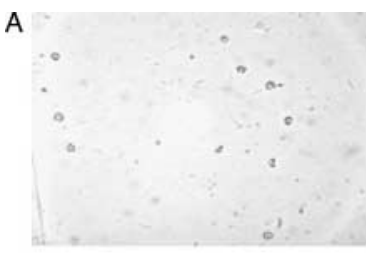

\section{Day 3}

C
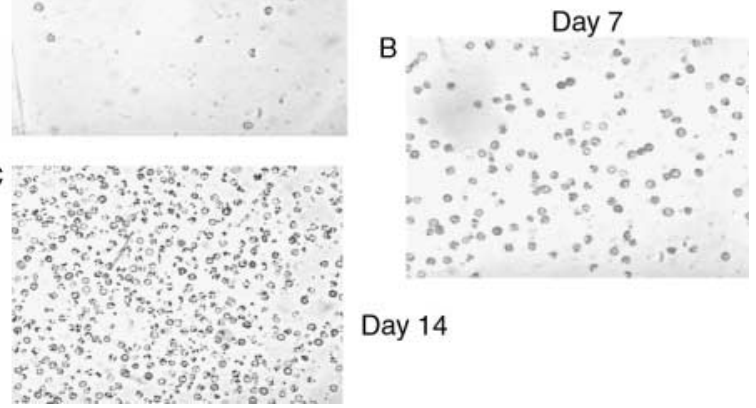

Day 14

Figure 1 Appearance of spheroids isolated from a human thyroid. (A) Phase contrast appearance of spheroids (HT21 line) isolated from one thyroid and kept in suspension culture $(10 \times$ magnification); a few spheroids appear in the suspension culture at time 0 ( 3 days from the beginning of the culture). (B) The same spheroid line has proliferated at time 1 ( 7 days from the beginning of the culture) and a higher number of spheroids appear at the same $10 \times$ magnification. (C) Phase contrast appearance of an even larger number of spheroids of the HT21 line, kept in suspension culture at time 2 (i.e. 14 days from the beginning of the culture).

was observed. Spheroids were again mechanically dissociated into single cells, resuspended in fresh medium and replated in new tissue culture plates. This procedure was repeated every 7 days, for an average time of 2 months (vide supra). In experiments conducted at different cell densities with spheroids consisting of about ten cells, PD time was estimated as $4 \cdot 6$ days, during the logarithmic phase, between 7 and 14 days from the start of the spheroid culture. Cumulative PD was calculated as $2 \cdot 6$.

The alternative procedure, a modification of the protocol employed for generating cardiospheres, was not effective in generating and expanding thyrospheres.

Proliferation assays verified that after 10 days $1 \cdot 1 \times 10^{5}$ cells $/ \mathrm{ml}$ were counted when spheroid cells were cultured in the presence of EGF-bFGF and $3 \times 10^{4}$ cells $/ \mathrm{ml}$ when cultured in the presence of EGF alone. Approximately, the number of cells increased threefold in 1 week in the two different culture conditions $\left(2 \cdot 6 \times 10^{5} / \mathrm{ml}\right.$ in the culture with EGF and bFGF and $9 \times 10^{4} / \mathrm{ml}$ in the presence of EGF alone). In wells where spheroid cells were cultured in the presence of bFGF alone, the number of cells was $8 \times 10^{4} / \mathrm{ml}$ after 1 week and increased to $1.8 \times 10^{5} / \mathrm{ml}$ after an additional week. These results demonstrate an additive effect when EGF and bFGF were added together to the spheroid culture medium, confirming to be the most efficient combination of growth factors.

Our method was successful in generating spheroids from the normal thyroid and from normal perinodular tissue of the thyroid adenomas as well as from all the different pathological thyroids. Spheroids consisted of small cells that tended to cluster (Fig. 2A), each single element showing a large nucleus and a narrow cytoplasmic ring (Fig. 2B), a morphology completely different from that of adult thyrocytes. Under our culture conditions, most of the cultures maintained a good proliferation 


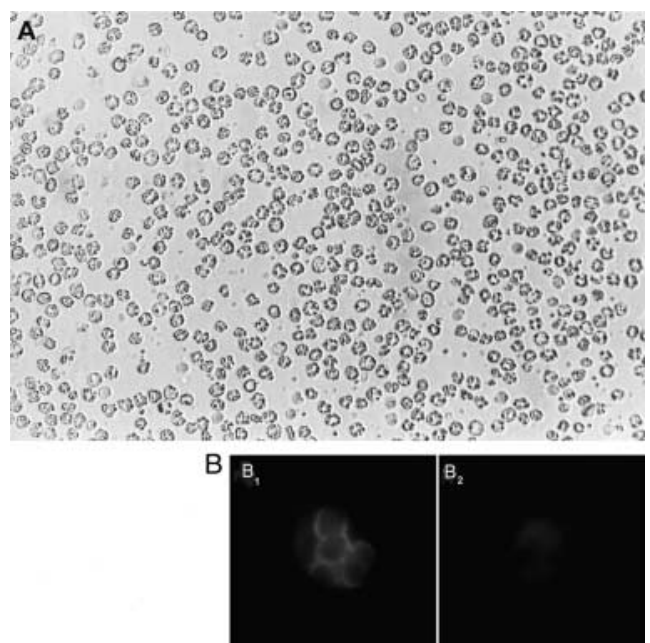

Figure 2 Appearance of spheroids isolated from a human thyroid. (A) Phase contrast appearance of a large number of spheroids isolated from another thyroid (HT22 line) and kept in suspension culture (20× magnification) after 45 days from the beginning of the culture. (B) Single spheroids stained by IFL with antibodies to Tg $\left(40 \times\right.$ magnification). On the left $\left(B_{1}\right)$, a single spheroid stained with an antiserum against Tg: cells within the spheroid have a large nucleus and a narrow cytoplasmic ring expressing $\mathrm{Tg}$. On the right, another single spheroid which does not express $\operatorname{Tg}\left(B_{2}\right)$.

rate. After 2 months from the start, culture of 'spheroids' had proliferated considerably to the point of generating lines (see Table 1). Lines were generated from all the individual 23 HTs initially obtained.
Proliferation assay of spheroids

Spheroids of the HT14 and HT56 lines were assessed starting 1 month from the generation (time 1) and after an additional 7 (time 2), 14 (time 3) and 21 days (time 4; Fig. 3) for their proliferation capacity. Between times 1 (Fig. 3A and B) and 2 (Fig. 3A1-B1), there was a reduction in the intensity of the fluorescent signal, indicating a significant proliferation in the progeny. At times 3 (Fig. 3A2-B2) and 4 (Fig. 3A3-B3), there was no reduction in the fluorescent signal intensity than that seen at time 1, but the number of positive events was progressively reducing, indicating that cells had reached logphase expansion and progressively became senescent. In vitro senescence was estimated at an average of 35 days in culture.

\section{Telomere length and telomerase expression}

Three lines of thyrospheres were rescued from tissue cultures after 2 months from their generation. In these cell cultures, as well as the original bioptic specimen, the expression of hTERT, the catalytic subunit of telomerase, was undetectable. It is predictable that without the catalytic subunit of telomerase, the telomeres will shorten with a rate that will be dependent on the cell type and culturing condition. The length of telomeres of these cell lines was measured by TRF method and compared with that of the original tissue, assuming bona fide that this was the telomere length at the beginning of culturing. During the cultivation time, the telomeres shortened about $2 \mathrm{~kb}$ (data not shown): in fact, the median values of the overall telomere length were $8.3 \mathrm{~kb}$

Table 1 Expression (\% positive) of thyroid differentiation markers (thyroglobulin (Tg), thyroperoxidase (TPO), thyrotrophin receptor (TSH-R) and $\mathrm{Na}^{+} / I^{-}$symporter (NIS)) and of stem cell markers in some lines of spheroids generated from surgical thyroid specimens. HT14, HT49, HT50 and HT56 were lines generated from normal thyroid tissue. HT18, HT21 and HT23 were lines generated from thyroids affected by Graves' disease; HT62, HT63 and HT66 were lines generated from apparently normal perinodular tissue of thyroid adenoma

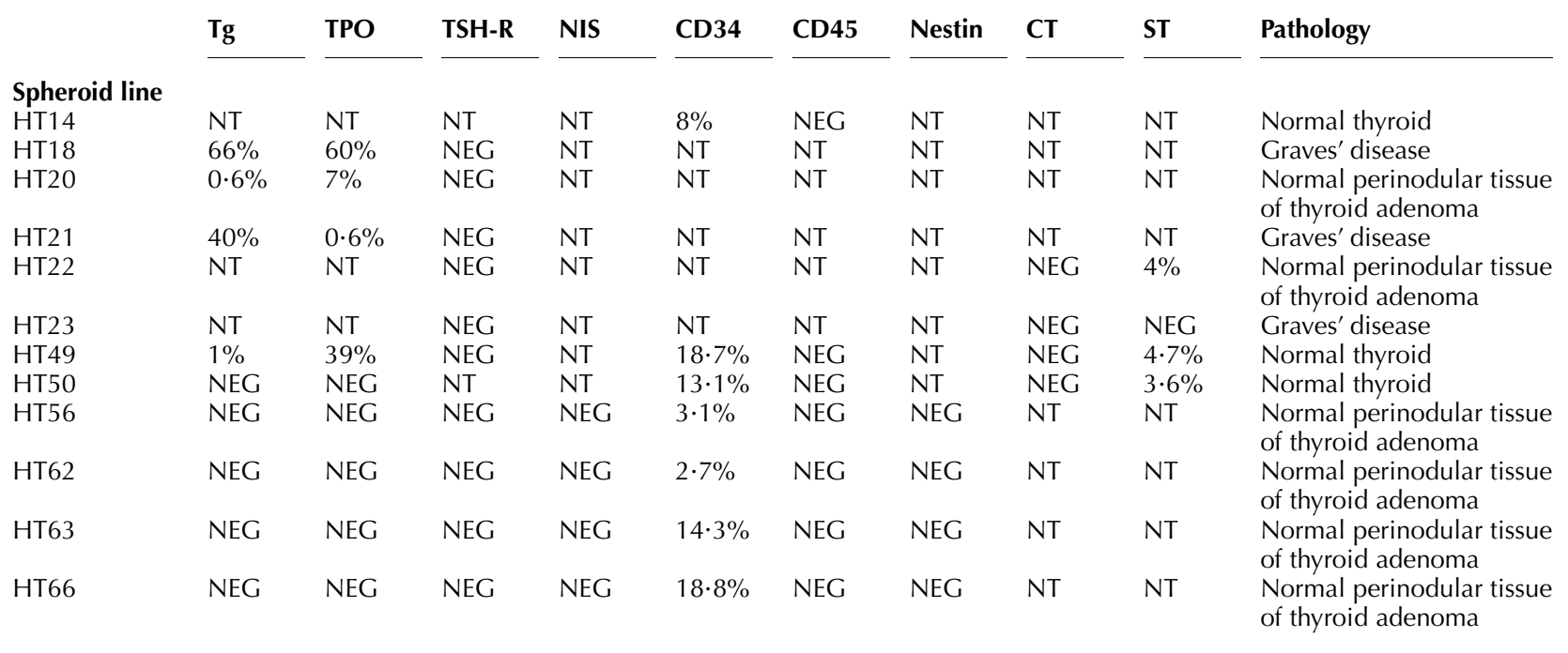

NEG, negative; NT, not tested. 

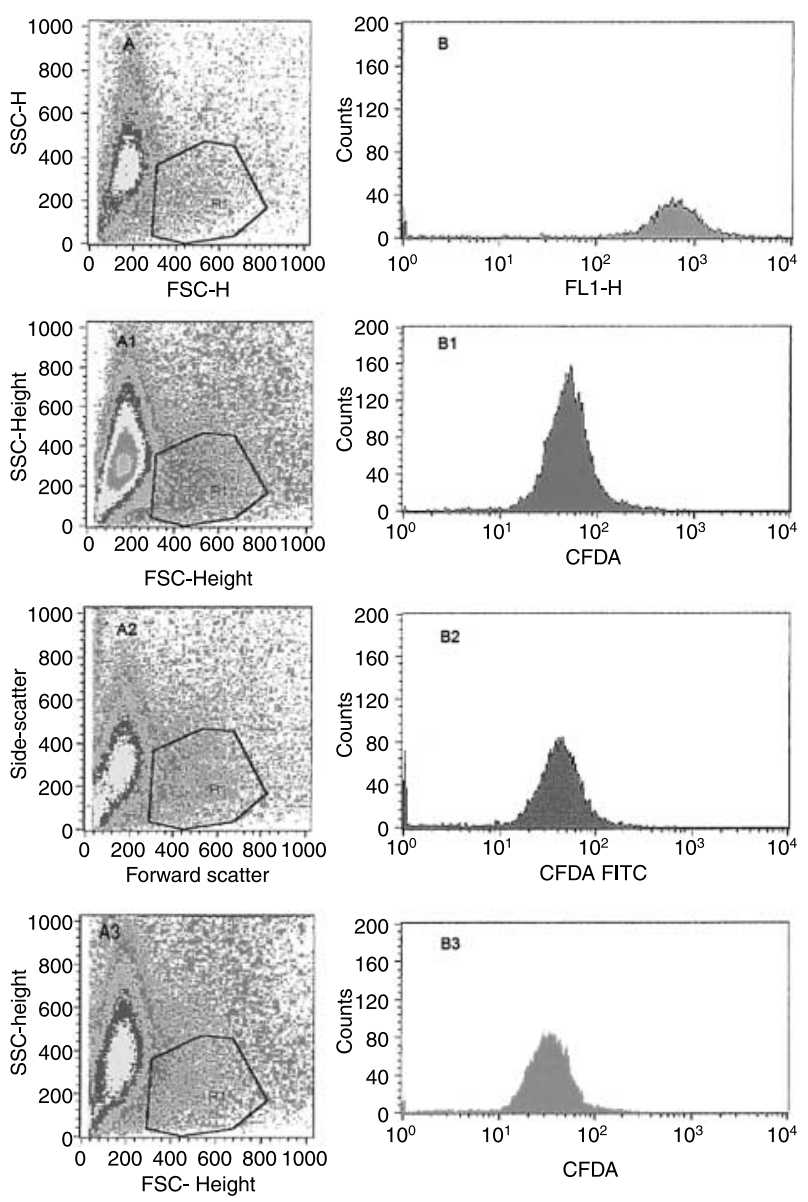

Figure 3 Proliferation assay of the HT56 line of spheroids. The spheroid line was stained with CFDA at time 1 (1 month after its generation) and fluorescence intensity analysed at time 1 and every 7 days in the long-term culture. A minimum of 20000 live cell events were collected and analysed by flow cytometry. (A-B) time 1; (A1-B1) time 2 (seventh day); (A2-B2) time 3 (fourteenth day); (A3-B3) time 4 (twenty-first day). (A) Dot Plots of FSC-H and SSC-H of spheroid line of gate R1. (B) Histogram plots of fluorescence intensity of CFDA-FITC of gate R1. Fluorescence intensity of CFDA decreases after 7 days of culture from time 1 , indicating a proliferation activity of spheroid cell line. In the subsequent times, a peak of an equal fluorescence intensity is shown, but distributed in a lower number of events, indicating that the line has reached the log phase, is not further proliferating.

in the original thyroid tissue and to $6 \cdot 5 \pm 0 \cdot 4 \mathrm{~kb}$ at the end of culturing.

\section{Clonogenesis}

Spheroids generated from the thyroid specimens were found to be composed of clonally derived cells and did not simply represent cellular aggregates (Fig. 4). When human CFDE-labelled spheroids were dissociated and plated by limiting dilution as single cells fluorescent spheres were generated with $1-10 \%$ efficiency.

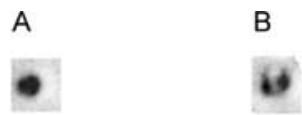

B

C

Figure 4 Clonogenesis experiment. The clonogenic origin of a single spheroid is monitored. (A) One single cell originating from the spheroid in a single well of a 96-well tissue culture plate.

(B) After 1 week from the same cell, a cluster of two cells is generated. (C) After additional 14 days, a spheroid composed of more than two cells is generated from the original spheroid cell (10× magnification).

Immunophenotyping of spheroids isolated from the human normal and pathological thyroids

Immunocytochemistry Spheroids of seven generated lines (HT14, HT18, HT20, HT21, HT22, HT23, HT49 and HT56) were tested.

By immunocytochemistry on coverslips or cytospun slides, a population of cells within the spheroids was found positive for $\mathrm{Tg}$, but no cells were positive for TPO or TSH-R expression. Within each generated line of spheroids, the percentage of $\mathrm{Tg}$ positive varied between 1 and $25 \%$ of the total population (Fig. $2 \mathrm{~B}_{1}$ ). In the spheroids kept in primary culture, the $\mathrm{Tg}$ expression was detected in them over a prolonged period; in particular, two cell lines were analysed at 12 and 16 weeks respectively and still found to express $\mathrm{Tg}$. HT56 line was negative.

FACS analysis Intra-cytoplasmic $\mathrm{Tg}$ expression was analysed in lines of spheroids generated from nine thyroids and found positive in four of them, at percentages varying from 0.6 to $60 \%$ of gated cells (see Fig. $5 \mathrm{~A}$ and Table 1). In parallel, TPO intra-cytoplasmic staining was analysed in nine lines and found positive in four. The percentage of positivity varied from 7 to $50 \%$ (see Fig. 5B and Table 1). No surface staining for TSH-R was detected in the ten lines examined (Fig. 6 and Table 1), so NIS was not expressed in four out of four lines
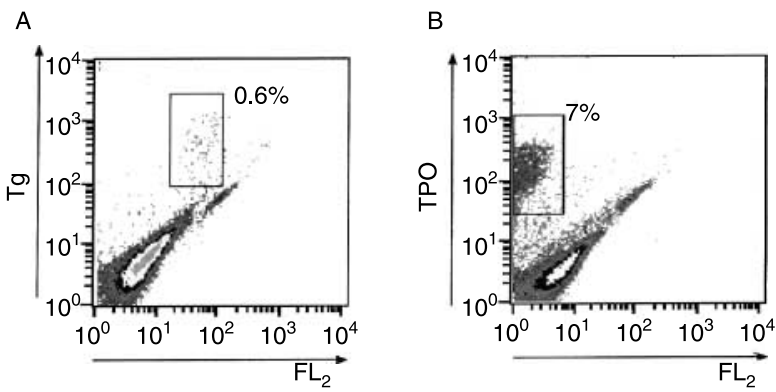

Figure 5 FACS analysis of the expression of thyroid differentiation markers in the HT20 line of spheroids. A minimum of 20000 live cell events were collected, using FACSCalibur flow cytometer (Becton \& Dickinson, San Jose, CA, USA) and analysed with CellQuest software (Becton \& Dickinson). Data are shown as density plot. (A) Intracytoplasmic thyroglobulin $(\mathrm{Tg})$ is present in $0 \cdot 6 \%$ of gated cells. A plot of FL1 (Tg) versus FL2 (no staining) is shown. (B) Intracytoplasmic thyroperoxidase (TPO) is present in $7 \%$ of gated cells. TPO expression (FL1) versus FL2 (no staining) is plotted. 

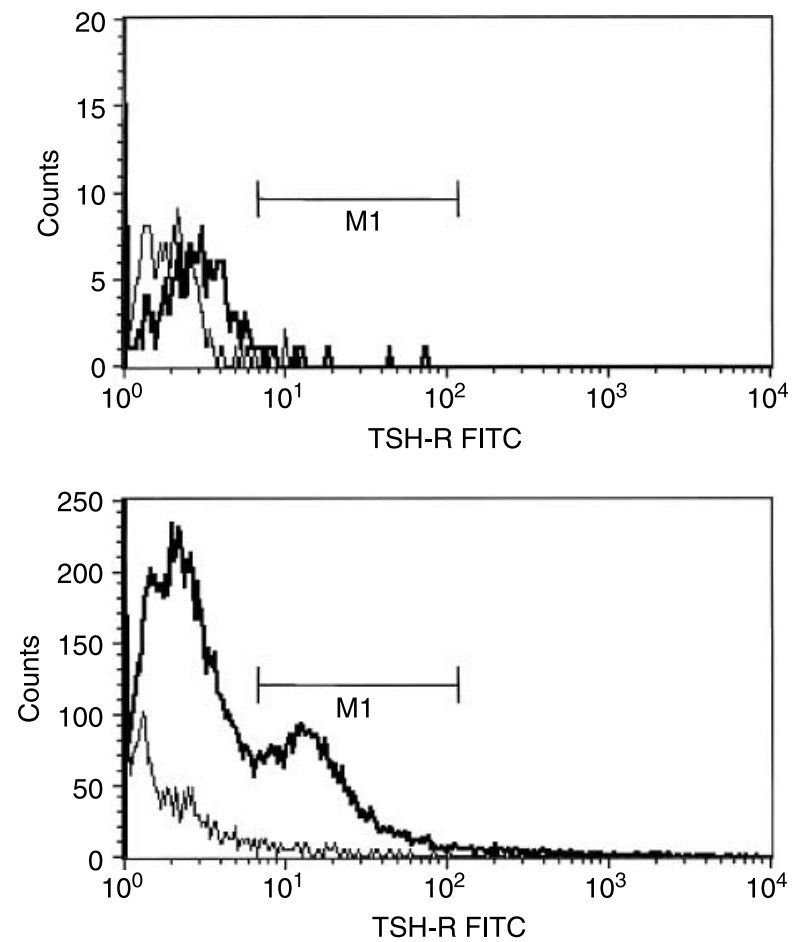

Figure 6 FACS analysis of the surface TSH-R expression in the HT21 line of spheroids. On the lower panel, a population of differentiated thyrocytes express the TSH-R (positive control): on the panel above, spheroids of the HT21 line do not show TSH-R expression.

examined, both at the surface and intra-cytoplasmic levels (data not shown). Five lines lacked all thyroid differentiation markers tested (Table 1). At the cytoplasmic level, the parafollicular cell marker calcitonin was detected in none of the four lines examined, while somatostatin was expressed in three out of four lines ( $\sim 4 \%$ of gated cells; not shown). Antibodies to common surface stem cell markers identified a subpopulation of CD34 + cells (1-25\%), but CD45 was not detected in all 12 lines examined (see Table 1 for CD45-negative expression in seven of these lines). The other stem cell markers, i.e. c-kit (examined in five out of ten lines) and AC 133/1-2 (examined in one out of ten lines) were both negative (see Fig. 7A). Nestin was not expressed in four out of four lines examined (Fig. 7B). Two lines were also tested for the expression of the endothelial cell differentiation markers CD144 and CD31; one of the two lines was found positive for CD144 in 2\% of gated cells, but both lines were negative for CD31 (data not shown). It would have been interesting to show whether $\mathrm{Tg}$ and TPO were co-localized in the same cells, or whether CD34 was co-localized with the other thyroid differentiation markers, but those experiments could not be performed, because MoAbs, directly conjugated with different fluorochromes, directed against these thyroid differentiation markers, are not available. Immunophenotyping was completed by testing the expression of 'stroma cell markers': Stro-1 expression was negative in three out of three lines examined, CD105 (SH2) expression was negative in two out of two lines examined, CD73 (SH3) expression was positive in two $(2 \cdot 7$ and $16 \%$ of gated cells) out of three lines examined and CD44 tested negative in the only one line examined (not shown).

Expression of nestin, pluripotency markers Oct-4 and Nanog on spheroids

Nestin is commonly expressed by neurospheres (Shih et al. 2001) and by multipotential stem cells from adult pancreatic islets (Zulewski et al. 2001). Nestin mRNA was detected in 12 spheroid lines (HT14, HT18, HT20, HT21, HT22, HT23, HT49, HT50, HT56, HT62, HT63 and HT66; see Fig. 8A), including those four lines that resulted negative, when analysed by flow cytometry (see Table 1 ). The expression of mRNA of pluripotency markers human Oct-4 and Nanog was found positive on five generated lines (HT51, HT62, HT63, HT69 and HT72; Fig. 8B and C).

\section{Morphological and functional studies}

Differentiation of cultured spheroids on collagen gel to obtain functional thyroid follicles Spheroids seeded in collagen gels in the presence of 'differentiation medium' after a few days tended to dissociate and started to generate 3D spherical colonies (not shown). The result was obtained with each of the three 'differentiation media' based on DMEMF12 nutrient, lacking EGF, bFGF and $\beta$-mercaptoethanol (see Materials and Methods). Spherical colonies were composed of cells with a more pronounced cytoplasmic compartment than that of the original long-term cultured spheroid populations or of control spheroids seeded in 3D cultures in the presence of EGF, bFGF and $\beta$-mercaptoethanol. After 3 weeks seeded in collagen, most of the outgrowths showed formation of follicle-like structures; the cells lining these structures were larger and had a more pronounced cytoplasmic compartment than that of the original spheroid population (see Fig. 9). By contrast, control spheroids cultured in 'spheroid culture medium' did not differentiate into follicle-like structures, but maintained a spheroid-type morphology (data not shown).

From each culture of spheroids seeded in collagen gel, we evaluated that an average of $50 \%$ gave rise to follicle-like structures with enlarged follicular lumen and increased height of follicular cells. Cells within the follicles were all positive for $\mathrm{Tg}$ (Fig. 10A), while TPO positivity was more evident in cells placed at the periphery of the follicles (Fig. 10B). Again the expression of TSH-R was not detected (not shown). Whether there was any NIS expression in the cells of the follicle-like structure remains doubtful, mainly because of the high background given by the reagents used for its visualization (data not shown). While $T_{3}$ and $T_{4}$ were not detected in the supernatants of the spheroids cultured in the spheroid medium, the levels of $\mathrm{T}_{4}$ progressively increased in the supernatant of the spheroids cultured in 'differentiation medium' (Fig. 11). Traces of $T_{3}$ were detected in the 
supernatants of both cultured spheroid preparations most probably due to amount present in the FBS (see Materials and Methods and Fig. 11). There was no significant production of calcitonin, while a slight increase in somatostatin was detectable after 3 weeks of culture in only one differentiated culture (Fig. 12). On a speculative basis, this result may be due to the paracrine differentiation of rare multipotent neural crest progenitors (Fierabracci et al. 1993, Dupin et al. 2007).
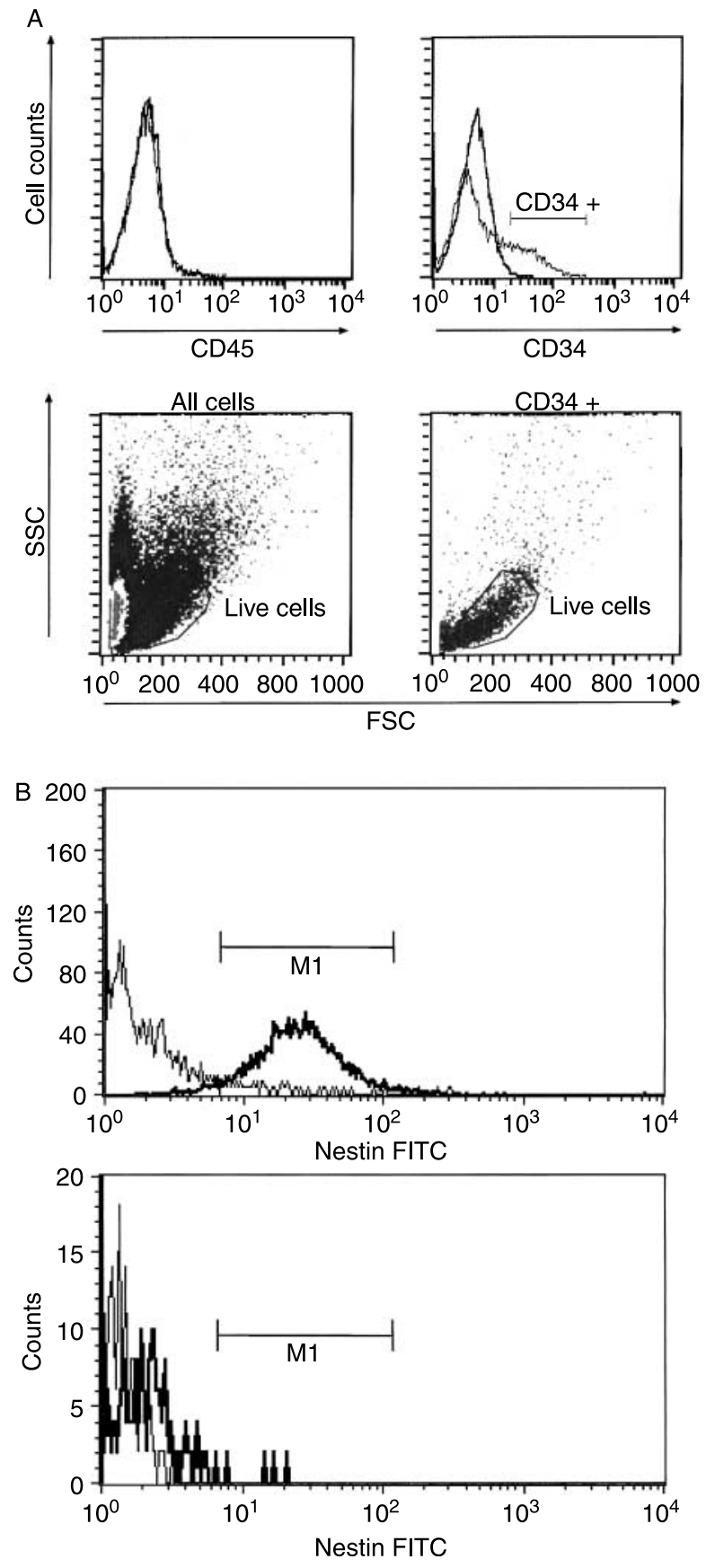

Co-culture of spheroids with a neuroblastoma cell line: the proof of 'plasticity' After 3-8 days from the start of the co-culture with the neuroblastoma cell line LAN5, the spheroids became larger and each single cell increased in volume. This was documented by direct visualization under the microscope of differentiating cells and spheroid cells (not shown). At the end of the 8-day co-culture period, a first aliquot of the spheroids was recovered and analysed by FACS. A population containing a high percentage of CFDA-positive cells was gated; the cells were bigger than the spheroids not co-cultured with the neuroblastoma cells, but smaller than the CFDA-negative neuroblastoma cells (Fig. 13). The neuronal marker $\beta$-tubulin III was expressed in $96 \%$ of the large CFDA-positive cells, which, most likely, derived from the original CFDA-positive spheroids that had acquired, one of the phenotypic characteristics of the neuronal lineage, during the co-culture period. Incidentally, before the beginning of the co-culture, the neuroblastoma cell line was confirmed to be positive for the neuronal marker $\beta$-tubulin III in all the cells. Flow cytometric analysis provided also the evidence that $20 \%$ of cells in the original spheroid population expressed $\beta$-tubulin III. The fact that $\beta$-tubulin III-positive cells became $96 \%$ in the CFDA-positive differentiating population can be interpreted to mean that only the particular subset of $\beta$-tubulin III-positive spheroid cells selectively expanded and differentiated into the new neuronal phenotype. Certainly, we have the demonstration of an intrinsic 'plasticity' of the spheroids derived from the thyroid, a characteristic that has been unmasked by factors produced by the CFDA-negative neuroblastoma cells.

The morphology of CFDA-positive spheroids was observed when a second aliquot was recovered from supernatants after 3-8 days of co-culture and separately cultured for an additional 2-3 days in the 'neuronal differentiation medium'. The labelled cells within spheroids appeared enlarged in their cytoplasmic content, sometimes with elongated shape, resembling the neuronal phenotype (Fig. 14A). When stained, these cells were positive for $\beta$-tubulin III (Fig. 14B) and neurofilaments, but negative for synaptophysin expression (data not shown).

Figure 7 Expression of stem cell markers on spheroids of the HT52 line. (A) FACS analysis. Cells were stained with MoAbs to CD45 and CD34. The fluorescence of cells stained with either the indicated MoAb (thin line) or the isotype control (thick line) is shown by the histograms (upper panels). CD45 is not expressed by the cell line (upper left panel), whereas $20 \%$ of the cells are positive for CD34 (indicated by the linear gate; upper right panel). MoAb anti-CD20 PE conjugated (1:10) and MoAb anti-CD4 FITC conjugated (1:10) were used as isotype controls. The density plots in the lower panels show FSC and SSC characteristics of all cells (lower left panel) and of cells expressing CD34 (lower right panel). The great majority of CD34+ cells are included in the gate of live cells. (B) FACS analysis of nestin expression. The fluorescence of cells stained with the MoAb antinestin followed by the anti-mouse FITC secondary antibody (thick line) and that of the secondary antibody alone (thin line) is shown. The upper panel refers to the positive control, i.e. the all primary cells obtained by the digestion of a fresh human thyroid; the lower panel shows the staining of the representative thyrosphere line. 


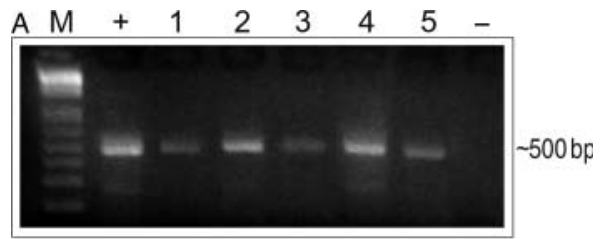

$M=$ molecular marker
$+=$ positive control

$-=$ negative control

B

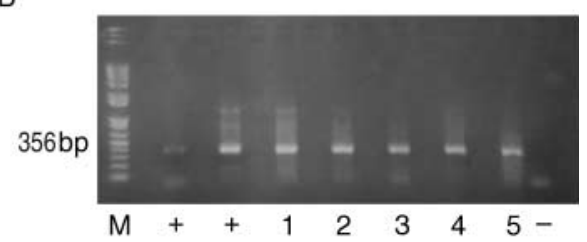

C

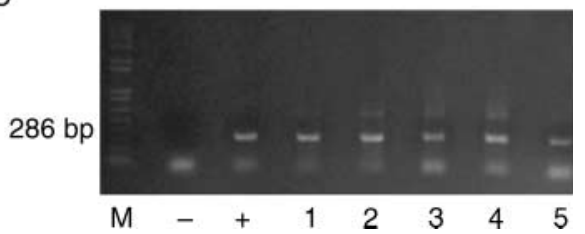

Figure 8 RT-PCR. (A) Nestin mRNA expression. This figure shows the presence of nestin mRNA in five lines (1-5) of thyrospheres (HT) examined. The positive control is represented by mRNA extracted from the all primary cells obtained by the enzymatic digestion of a fresh human thyroid. (B) Oct-4 mRNA expression. The presence of Oct-4 mRNA in five lines (1-5) of thyrospheres is shown. Positive controls (controls 1 and 2) were represented by mRNA extracted from human CD34+ haematopoietic cells. (C) Nanog mRNA expression. The presence of Nanog mRNA in five lines (1-5) of thyrospheres is shown.

\section{Mesenchymal lineage differentiation}

Adipogenic and osteogenic differentiation. Approximately, 35\% of spheroids underwent adipogenic differentiation consisting in enlarged cytoplasmic compartment (Fig. 15), containing

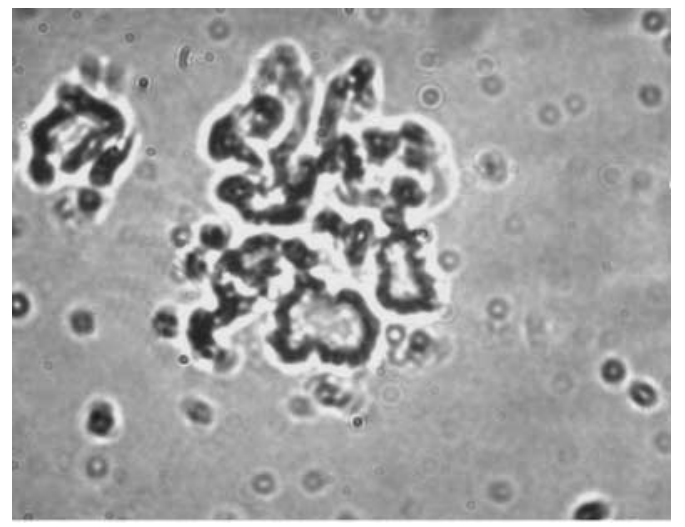

Figure 9 Differentiation of spheroids seeded in 3D collagen gels. Functional studies. Appearance of 3D spherical colonies generated from spheroids after they have been seeded in collagen gels in the presence of 'differentiation' medium for three weeks from the start of the culture in 3D collagen gels; spherical colonies show follicular organization at contrast microscopy ( $40 \times$ magnification).
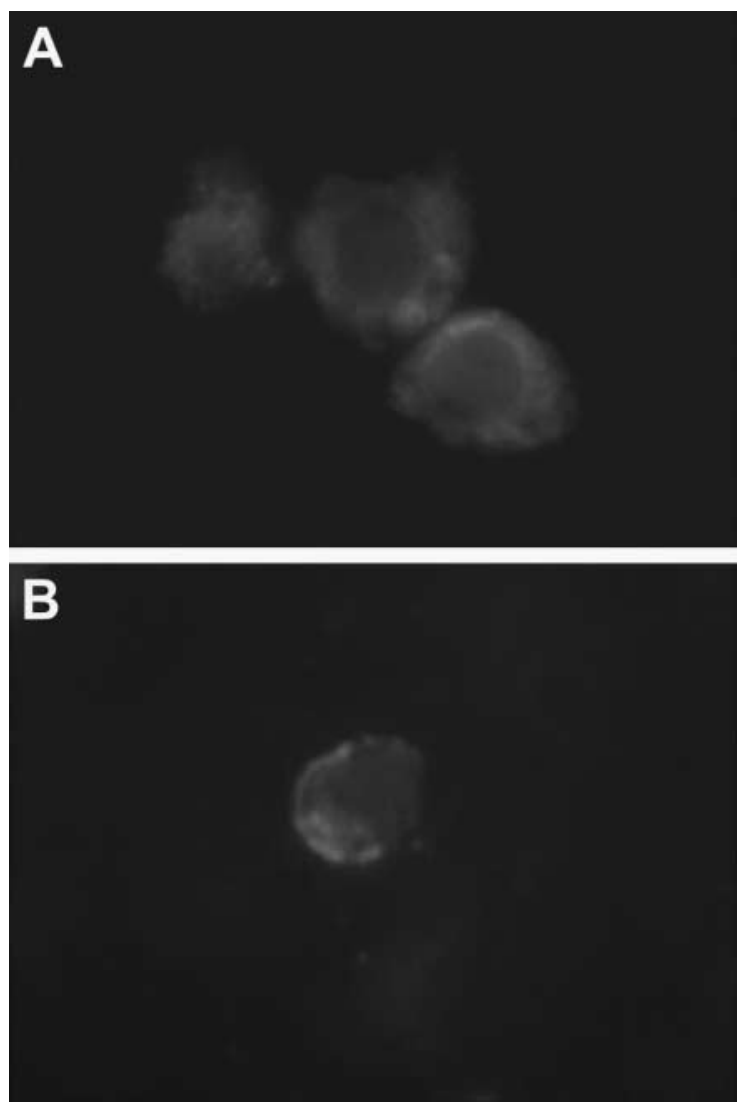

Figure 10 Differentiation of spheroids seeded in 3D collagen gels. Follicle-like structures obtained in 3D collagen gels are stained by IFL with antibodies to Tg and TPO. (A) Follicles express Tg.

(B) Another follicle expresses TPO (A and B, $40 \times$ magnification).

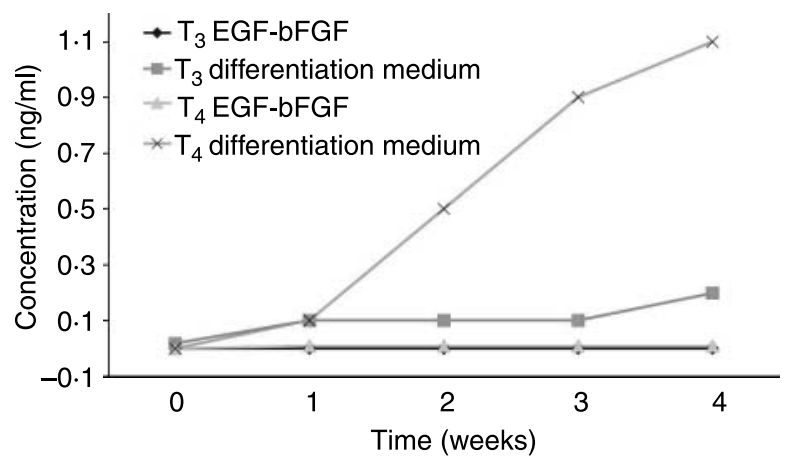

Figure 11 Measurements of $T_{3}$ and $T_{4}$ on culture supernatants of spheroids seeded in 3D collagen gels. Spheroids were kept either in the presence of differentiating medium or in basal conditions with $E G F, b F G F$ and $\beta$-mercaptoethanol. A significant increase in $T_{4}$ is detected in supernatants of spheroids cultured with differentiating medium compared with those cultured in basal conditions; $\mathrm{T}_{3}$ levels are negligible. 


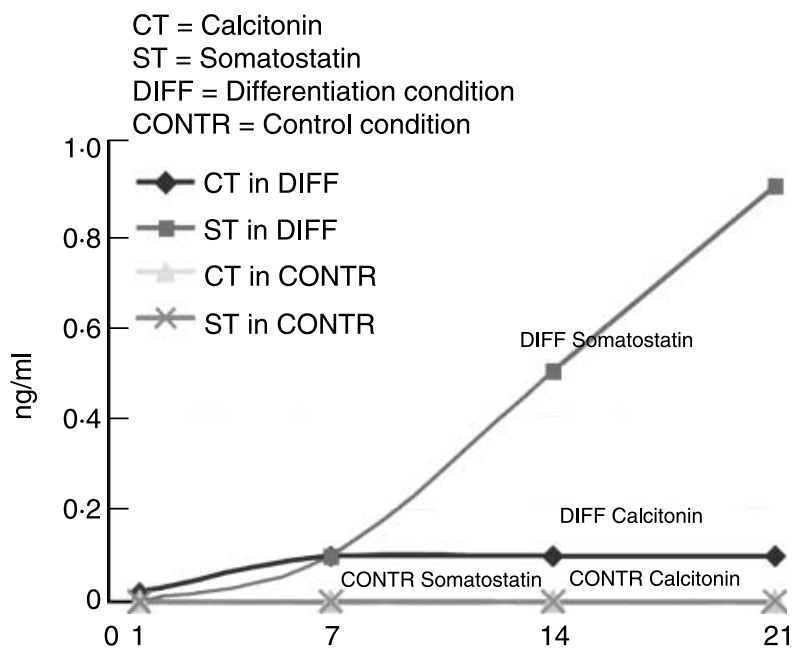

Figure 12 Measurement of calcitonin and somatostatin on culture supernatants of spheroids seeded in 3D collagen gels. Spheroids were kept in the presence of differentiating medium or in basal conditions with EGF, bFGF and $\beta$-mercaptoethanol. The figure shows an increase in somatostatin (ST) detected in the supernatant of only one spheroid line cultured with differentiating medium compared with those cultured in basal conditions; calcitonin (CT) levels are negligible.

multiple, intracellular lipid-filled droplets positive to oil red $\mathrm{O}$ staining. In control slides of spheroids cultured in 'spheroid culture medium', few or no undifferentiated spheroid cells stained positive to oil red $\mathrm{O}$. We did not observe morphological changes of osteogenic differentiation in spheroids after culture in $\mathrm{OM}$ as well as in spheroids cultured in parallel in 'spheroid culture medium'. Both preparations stained negative to Von Kossa (data not shown).

In vivo experiments to assess tumorigenicity and histological examination Xenografted SCID mice did not develop tumours within the period of observation of 2 months, as assessed by gross anatomy in the site of thyrospheres injection, either subcutaneously or intra-organ (i.e. testis, liver). By IFL staining with the anti-human MHC class I L31 MoAb, the injected human cells were visualized with an elongated morphology (data not shown).

\section{Discussion}

The methodology we have devised has successfully led to the identification and characterization of a population of spheroids from the adult human normal thyroid, similar for morphological appearance and long-term culture characteristics to neurospheres (Shih et al. 2001). Important considerations derive from examining the experimental procedures that have been separately implemented for isolating stem/progenitor cells from different organs (Alessandri et al. 2004, Messina et al. 2004, Fierabracci et al. 2007, Puglisi et al. 2008). In the common procedure adopted in all these systems to isolate spheroids, the 'spheroid medium' selects undifferentiated cells, reduces the proliferation of differentiated cells, while the absence of serum prevents stem cell differentiation (Vescovi et al. 1993).

Three different populations of cells can be distinguished within spheroid lines obtained from normal and pathological thyroids: 1) 'true stem cells' that did not express any of the markers tested; 2) cells that express the 'so-called'stem cell marker CD34 and 3) progenitor cells that already have reached a partial commitment. We can speculate that the 'true' stem cells may subsequently acquire the 'stem cell' CD34 marker in a variable percentage within the different thyrosphere lines. The importance of identifying additional surface markers, specific for the 'true' stem cells contained in solid organs is emphasized by the fact that a large proportion of cells remains negative for all markers tested. However, the lack of expression of the CD45 in our thyrosphere lines excludes a possible contamination of haematopoietic derived stem cells (Bonnet 2002). It is relevant to underline the expression at mRNA level of pluripotency markers Oct-4 and Nanog (Pain et al. 2005) in all the lines examined.

A further characterization of the thyrospheres was the analysis of the telomere length and of the telomerase enzyme. The telomeres, the specialized structures that seal chromosome ends, shorten during duplication of most cells. This process may be counteracted by telomerase, a ribonucleoprotein complex regulated by the catalytic subunit hTERT. Without telomerase, telomeres shorten to a length, which trigger cell senescence. The thyrospheres lines analysed did not present detectable expression of hTERT and the length of the telomeres was of about $6 \cdot 5 \mathrm{~kb}$. Thus, the telomere length of senescent cell cultures was compatible with the telomere hypothesis of cell senescence.

According to modern views, an important characteristic of a stem cell is its 'plasticity' (Blau et al. 2001), which implies that adult stem cells may have an intrinsic regulatory function, rather than being just a discrete cellular entity. Regarding this issue, we proved that the generated thyrosphere lines could be directed to differentiate towards the thyroidal phenotype, at least achieving a partial differentiation. We can suggest that in the thyroidal differentiation process two different possibilities exist: either the population expressing thyroid differentiation markers is the one that, being already committed, do differentiate into thyroid cells, or even the real stem cell population contributes to the differentiation process by moving through the stage of progenitor cell compartment to the final adult cell.

In the $3 \mathrm{D}$ differentiation culture system, thyrospheres indeed formed follicular structures, acquired a polar orientation and produced $\mathrm{T}_{4}$; there was no $\mathrm{T}_{4}$ production, when thyrospheres lines were grown and expanded in 'spheroid medium' in the standard culture dishes and not in the 3D system. EGF and bFGF, added together, were able to maintain in culture the spheroids isolated from the thyroids and to sustain their long-term proliferation, but, as demonstrated for neurospheres, in particular, EGF could have been responsible for exerting an inhibitory effect on the functional differentiation of the thyroid progenitor cells. $\beta$-Mercaptoethanol was 

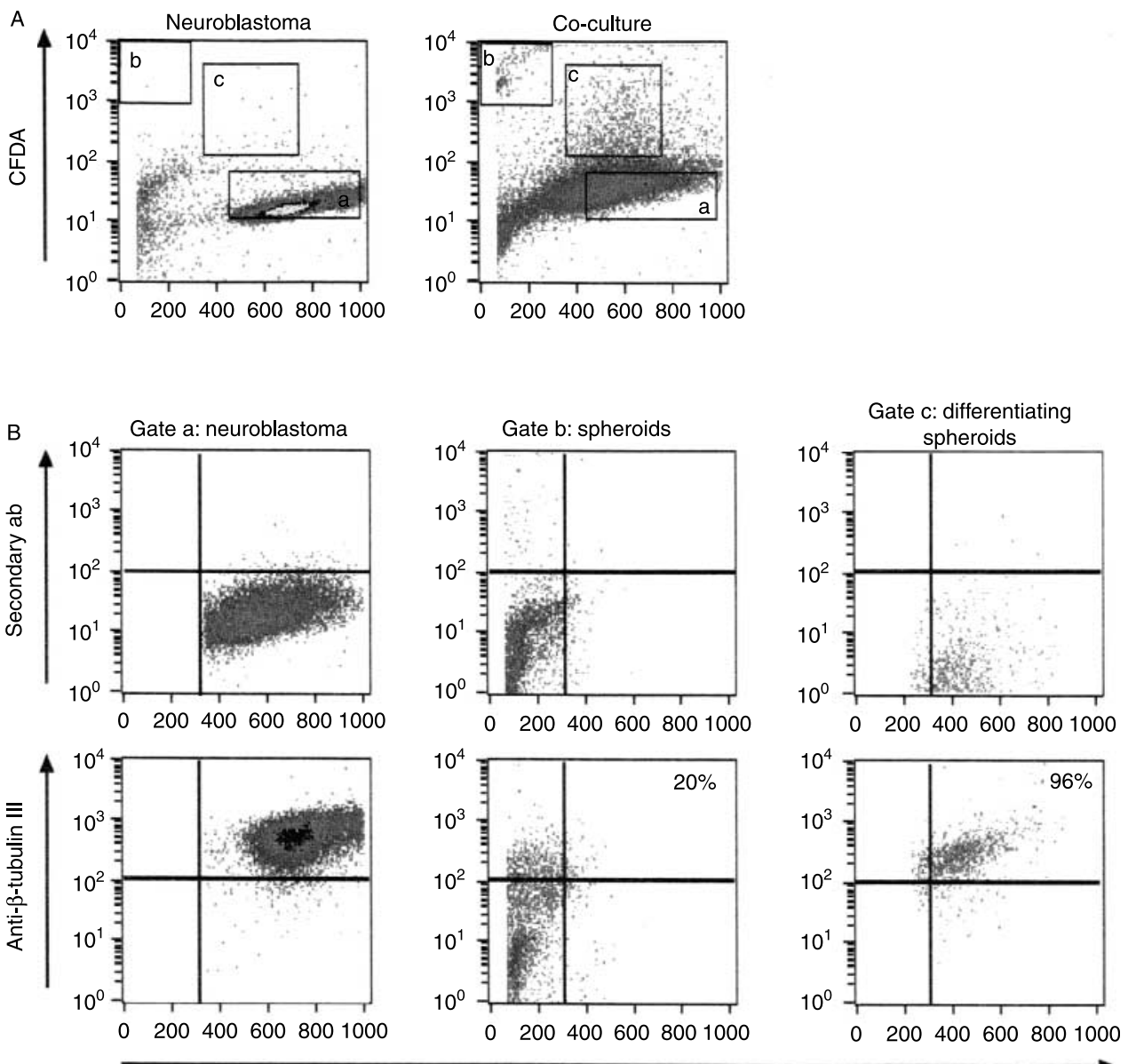

Forward scatter

Figure 13 Co-culture of the HT56 line of spheroids with a neuroblastoma cell line induces the expression of the neuronal marker $\beta$-tubulin III. To identify the different cell types, physical parameters (forward scatter) and fluorescence (CFDA labelling of spheroids cells) were used. (A) Neuroblastoma cells cultured alone (left panel) or together with the HT56 line (right panel) appear in the ' $a$ ' gate, spheroid cells are either small and resting (gate ' $b$ ') or larger and proliferating (gate ' $c$ ', progressive loss of CFDA and increased size).

(B) $\beta$-tubulin III is expressed in all neuroblastoma cells (gate ' $a$ ' shown in bottom left panel). Twenty per cent of spheroid cells were positive for this marker in basal conditions (gate ' $b$ ', bottom middle panel), but virtually all differentiating spheroid cells (gate ' $c$ ', bottom right panel) expressed $\beta$-tubulin III.

added because it is known to contribute to the proliferation of certain stem cells, such as haematopoietic stem cells (Ishikawa \& Ito 1988, Noble et al. 2003).

To make the 'spheroid differentiation medium', we therefore removed EGF, bFGF and $\beta$-mercaptoethanol and added 'differentiating factors'; we used either FBS alone, or FBS in combination with 8-Br-cAMP and TSH, or FBS in combination with TSH that was added to possibly engage rare TSH-R molecules, expressed on the spheroids even at low concentration, although TSH-R was never visualized by flow cytometry. The reason for adding 8-Br-cAMP (Montminy 1997) to the medium was to see whether it could provoke on its own the cascade of differentiating events (i.e. by-passing the TSH-R, in case this was absent). Nevertheless, significant levels of $\mathrm{T}_{4}$ were obtained in the presence of FBS alone.
The other combinations of factors did not induce further significant increase in $T_{4}$ production. On a speculative basis, the synergistic effect of FBS, insulin and transferrin may be able to engage the activation of the cAMP signalling and cAMP-protein kinase A cascade of events (Montminy 1997).

Despite the absence of TSH from the culture medium, thyrospheres differentiated into cells that produced significant levels of $T_{4}$. This is not surprising because thyrocytes are anatomically a heterogeneous cell population, with individual degrees of cell autonomy and an intrinsic capacity for colloid endocytosis, even in the absence of TSH (Studer et al. 1989).

It was previously reported (Toda et al. 2003) that, in 3D collagen cultures, folliculogenesis occurred at the periphery of thyroid tissue fragments (the regenerative site of the gland), in a TSH-free and calcium-independent manner. Similarly, in 

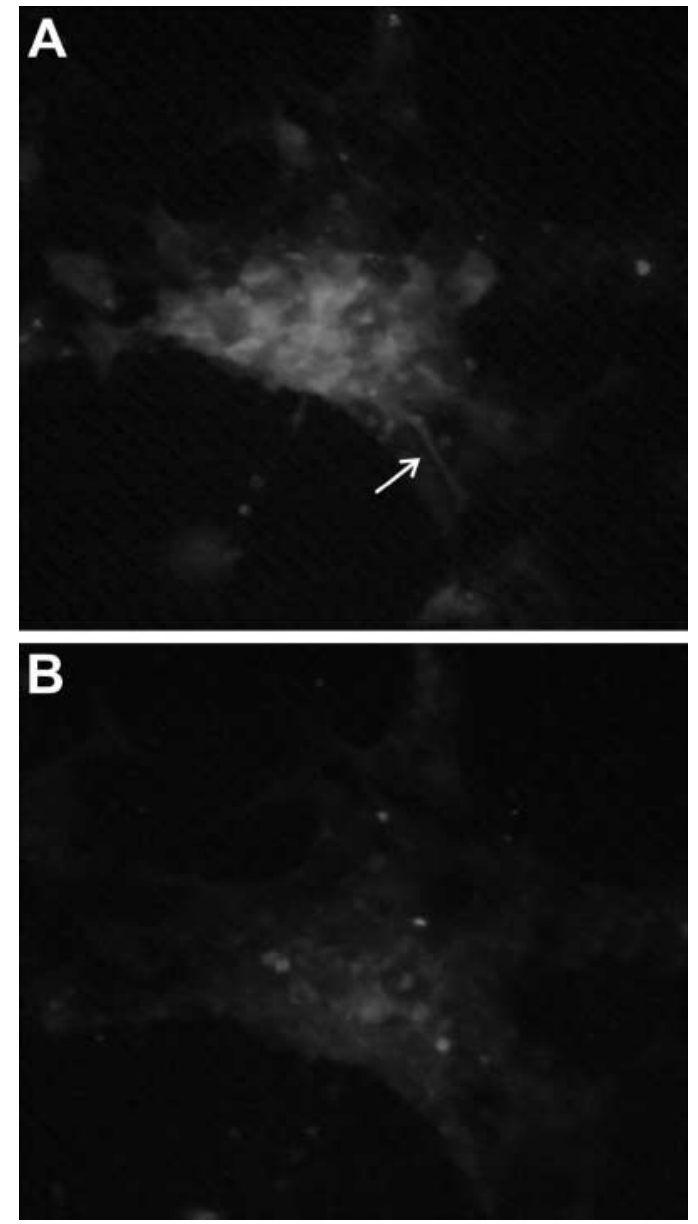

Figure 14 Extended culture of CFDA-positive spheroids recovered from the co-culture with the neuroblastoma cell line.

(A) Appearance of CFDA-positive differentiated spheroids that show elongated morphology and large cytoplasmic compartment with occasional neural-like processes (indicated by arrow). (B) Cells express $\beta$-tubulin III.

our experiments, folliculogenesis, and therefore potential tissue regeneration, occurred starting from stem/progenitor cells; like the $\mathrm{T}_{4}$ production by follicle-like structures, this also occurred in a TSH-independent manner in the 3D system. Another observation relates to the fact that when we cultured thyrospheres lines in 3D system, in the presence of 'spheroid culture medium', only occasional spontaneous follicle formation was observed, implying that there is a synergistic effect of the 3D culture system and the addition of FBS in the morphological differentiation into follicles.

The significant levels of $T_{4}$, without $T_{3}$ production, is in concord with a normal thyroidal cell physiology; $T_{3}$ production mostly derives from $\mathrm{T}_{4}$, due to the effect of deiodase activity exerted in extraglandular tissues (Braverman \& Utiger 1991).

It is remarkable that the newly generated follicular structures expressed most of the phenotypic characteristics

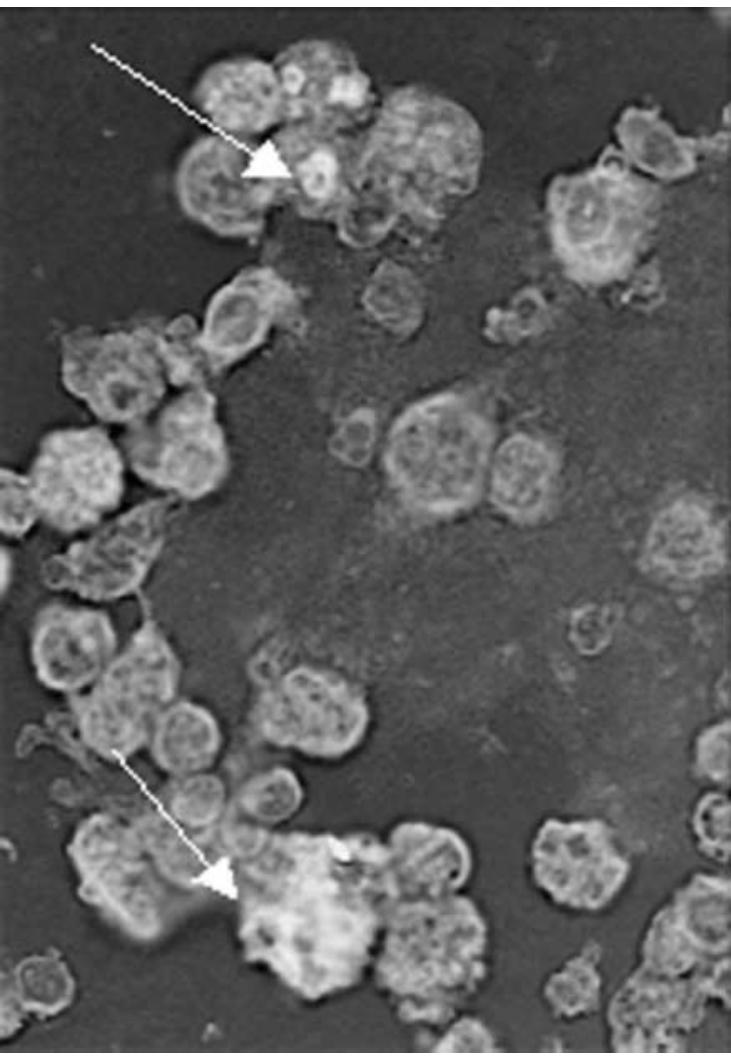

Figure 15 Adipogenic differentiation of spheroid cells after 3 weeks in adipogenic medium. We visualized lipid vacuole accumulation in cells within differentiated spheroids $(60 \times$ magnification).

of typically differentiated thyrocytes, i.e. Tg and TPO, but still lack TSH-R and NIS expressions, at least as revealed by immunocytochemistry and with the currently available MoAbs. This makes it difficult to speculate whether they could indeed reach the stage of fully differentiated 'perfect' thyrocyte. It would have been nice to prove the co-localization of $\mathrm{Tg}$ and TPO in the same cell, but anti-Tg and anti-TPO MoAbs directly conjugated with different fluorochromes are not available and it is impossible to perform double staining with an indirect IFL technique, because the second antibody would react with both mouse MoAbs. We performed double stainings with a rabbit polyclonal anti-Tg and the same MoAb anti-TPO, but the result was difficult to interpret because of the high background staining given by the first reagent.

The expression of NIS was always negative in our thyrosphere lines when analysed by flow cytometry, and it was uncertain in differentiated collagen gel cultures mainly because of the high background given by the reagents employed for its visualization. However, we need to point out that, independent of the sensitivity of the method employed, NIS expression is generally heterogeneous in thyroid specimens and strictly correlated with a high functional 
activity and iodide-trapping avidity of thyrocytes (Tonacchera et al. 2004). As mentioned above, our differentiated cells may not be highly differentiated thyrocytes. We are confident that the results of the immunophenotyping performed by FACS provide a valid characterization of the generated lines, because they reveal the presence of the expressed protein, i.e. Tg and TPO. It would have been interesting to correlate, when material was available from the generated lines, their phenotypic expression pattern with RT-PCR data. Nevertheless, RT-PCR would have only provided information at the mRNA level, but not of the corresponding protein expression.

A special consideration can be addressed when comparing the method we devised for the isolation, expansion and characterization of the thyrospheres in the human normal thyroid with that recently employed for isolating them from human goitres (Lan et al. 2007; Rev in Thomas et al. 2008). In the Lan's study, quiescent stem cells were separated by FACS as a side population by the Hoechst 33342 efflux technique, from a non-side population fraction that consisted of endodermal markers-positive cells and thyroid cells. Side population cells were negative for thyroid differentiation markers. Growth and expansion of stem cells from human goitres was achieved using a growth factor-enriched medium consisting of serum-free DMEM/Ham's F12 containing B27, EGF and bFGF, but lacking $\beta$-mercaptoethanol and the defined hormone and salt mixture we adopted (vide supra). In addition, intense growth stimulation of stem cells was obtained in co-culture with thyrocytes, while our thyrospheres were growing in suspension cultures, after tissue fragments residual to digestion were plated and thyrocytes discarded. Similar to our investigation, their thyrospheres differentiated into thyrocytes-like cells in a 3D collagen culture system, but after enzymatic dissociation. Nevertheless, only in response to TSH and serum, were they were able to produce thyroid-like cells that expressed PAX8, Tg, NIS, TSH receptor, TPO at the mRNA level and showed TSHdependent ${ }^{125}$ iodide uptake, although a typical thyroid hormone production was not reported. In addition, data from long-term culture experiments were not reported and no evidence was provided for the clonogenicity of their cells in vitro and their multilineage differentiation in vivo, which are critical for the recognition of a tissue-specific adult stem cell.

To further support their 'plasticity', spheroids co-cultured with the neuroblastoma cell line did indeed develop into cells which were larger and able to express the neuronal marker $\beta$-tubulin III. Spheroids also differentiated towards the adipogenic lineage. Unfortunately, it was not possible to perform all the different kinds of morphological and functional analysis from all the different generated lines due to the variable amount of spheroids.

We are aware that in vivo data would be highly beneficial to confirm differentiation and functionality of thyrospheres. We were able to verify the non-tumorigenicity of thyrospheres by injecting them into SCID mice (Greiner et al. 1998). Nevertheless, a suitable SCID hypothyroid animal model, ideal for verifying a possible in vivo differentiation towards the adult functional thyroidal cell type of xenografted thyrospheres, to our knowledge, has not been implemented so far (reviewed in Kasuga et al. 1991, McLachlan et al. 2005). The hypothyroid mice model, obtained throughout an accurate standardization, would still need to possess partial residual functional thyroid, producing factors necessary to induce the in vivo differentiation.

In summary, we have described a new predominant functional stem/progenitor cell in the normal HT producing additional evidence that the human adult thyroid is not a terminally differentiated organ, having a potential for intrinsic regeneration. The possibility of isolating and growing adult stem/progenitor cells from human organs sets the stage for future developments in regenerative medicine.

\section{Declaration of interest}

There is no conflict of interest that would prejudice the impartiality of this scientific work.

\section{Funding}

The work was supported by grants from the Italian Ministry of Health.

\section{Acknowledgements}

We would like to thank Dr O Porzio of the Department of Biochemistry, University of Tor Vergata, Rome, for the $\mathrm{T}_{4}$ and $\mathrm{T}_{3}$ assay on culture supernatants, Prof. P Carayon, Universitè de la Méditerranée, Marseille Cédex for providing anti-TPO MoAbs and Dr S Costagliola, IRBHM, Universitè Libre de Bruxelles, Bruxelles, Belgium for providing anti-NIS MoAb. We would like to thank also Dr R Carsetti and Dr E Giorda for their flow cytometry expertise and Dr E D' Ambrosio of the INMR, CNR, Rome for discussion on telomere and critical reviewing the manuscript.

\section{References}

Alessandri G, Pagano S, Bez A, Benetti A, Pozzi S, Cannolo G, Baronio M, Invernici G, Caruso A, Muneretta C et al. 2004 Isolation and culture of human muscle-derived stem cells able to differentiate into myogenic and neurogenic cell lineages. Lancet 364 1872-1883.

Blau HM, Brazelton TR \& Weimann JM 2001 The evolving concept of a stem cell: entity or function? Cell 105 829-841.

Bonnet D 2002 Haematopoietic stem cells. Journal of Pathology 197 430-440. Braverman LE \& Utiger R 1991 The thyroid. A fundamental and clinical text. In Werner and Ingbar's, edn 7. Philadelphia: Lippincott-Raven.

Curcio F, Ambesi-Impiombato FS, Perrella G \& Coon HG 1994 Long-term culture and functional characterization of follicular cells from adult normal human thyroids. PNAS 91 9004-9008.

Damante G, Tell G \& Di Lauro R 2001 A unique combination of transcription factors controls differentiation of thyroid cells. Progress in Nucleic Acid Research and Molecular Biology 66 307-356.

Dupin E, Calloni G, Real C, Gonçalves-Trentin A \& Le Douarin NM 2007 Neural crest progenitors and stem cells. Comptes Rendus Biologies 330 521-529.

Fargeas CA, Corbeil D \& Huttner WB 2003 AC133 antigen, CD 133, prominin -1 , prominin 2 etc: prominin family gene products in need of a rational nomenclature. Stem Cells 21 506-508.

Journal of Endocrinology (2008) 198, 471-487 
Fierabracci A, Castagna M \& Baschieri L 1993 Calcitonin and somatostatin containing $\mathrm{C}$ cells in rat and human thyroid. Immunohistochemical study by a double-staining method. Pathologica 85 467-474.

Fierabracci A, Upton CP, Hajibagheri N \& Bottazzo GF 2001 Lack of detection of retroviral particles (HIAP-1) in the H9 T cell line co-cultured with thyrocytes of Graves' disease. Journal of Autoimmunity 16 457-462.

Fierabracci A, Caione P, Di Giovine M, Zagaglia D \& Bottazzo GF 2007 Identification and characterisation of adult stem/progenitor cells in the human bladder (Bladder spheroids): perspectives of application in pediatric surgery. Pediatric Surgery International 23 837-839.

Galli R, Gritti A, Bonfanti L \& Vescovi AL 2003 Neural stem cells. An overview. Circulation Research 92 598-608.

Goodell MA, Brose K, Paradis G, Conner AS \& Mulligan RC 1996 Isolation and functional properties of murine hematopoietic stem-cells that are replicating in vivo. Journal of Experimental Medicine $\mathbf{1 8 3}$ 1797-1806.

Greiner DL, Hesselton RA \& Shultz LD 1998 SCID mouse models of human stem cell engraftment. Stem Cells 16 166-177.

Gritti A, Parati EA, Cova L, Frolichsthal P, Galli R, Wanke E, Favarelli L, Morassutti DJ, Roisen F, Nickel DD et al. 1996 Multipotential stem cells from the adult mouse brain proliferate and self-renew in response to basic fibroblast growth factor. Journal of Neuroscience 16 1091-1100.

Gritti A, Bonfanti L, Doetsch F, Caille I, Alvarez-Buylla A, Lim DA, Galli R, Verdugo JM, Herrera DG \& Vescovi AL 2002 Multipotent neural stem cells reside into the rostral extension and olfactory bulb of adult rodents. Journal of Neuroscience 22 437-445.

Horner PJ \& Gage FH 2000 Regenerating the damaged central nervous system. Nature 407 963-970.

Hoshi N, Husakabe T, Taylor BJ \& Kimura S 2007 Side population cells in the mouse thyroid exhibit stem/progenitor cell-like characteristics. Endocrinology 148 4251-4258.

Ishikawa Y \& Ito T 1988 Kinetics of hemopoietic stem cells in a hypoxic culture. European Journal of Haematology 40 126-129.

Johnstone AP, Cridland JC, DaCosta CR, Harfst E \& Shepherd PS 1994 Monoclonal antibodies that recognize the native human thyrotropin receptor. Molecular and Cellular Endocrinology 105 R1-R9.

Kasuga Y, Matsubayashi S, Sakatsume Y, Akasu F, Jamieson C \& Volpé R 1991 The effect of xenotransplantation of human thyroid tissue following radioactive iodine-induced thyroid ablation on thyroid function in the nude mouse. Clinical and Investigative Medicine 14 277-281.

Korbling E \& Estrov Z 2003 Adult stem cells for tissue repair. A new therapeutic concept? New England Journal of Medicine 349 $570-582$.

Kusunoki T, Nishida S, Koezuka M, Murata K \& Tomura T 2001 Morphological and functional differentiation of human thyroid cells in collagen gel culture. Auris, Nasus, Larynx 28 333-338.

Kusunoki T, Nishida S, Murata K \& Tomura T 2002 Correlation between morphology of colonies formed by human thyroid tumor cells in collagen gel culture and invasive ability. Thyroid 12 281-286.

Lan L, Cui D, Nowka K \& Derwahl M 2007 Stem cells derived from goiters in adults form spheres in response to intense growth stimulation and require TSH for differentiation into thyrocytes. Journal of Clinical Endocrinology and Metabolism 92 3581-3688.

Lin R-Y 2007 New insights into thyroid stem cells. Thyroid 17 1-5.

Lin R-Y, Kubo A, Keller GM \& Davies TF 2003 Committing embryonic stem cells to differentiate into thyrocyte-like cells in vitro. Endocrinology 144 2644-2649.

Lyons AB 1999 Divided we stand: tracking cell proliferation with carboxyfluorescein diacetate succinidyl ester. Immunology and Cell Biology 77 509-515.

McLachlan SM, Nagayama Y \& Rapaport B 2005 Insight into Graves' hyperthyroidism from animal models. Endocrine Reviews 26 800-832.

Messina E, De Angelis L, Frati G, Morrone S, Chimenti S, Fiordaliso F, Salio M, Battaglia M, Latronico MVG \& Coletta M 2004 Isolation and expansion of adult cardiac stem cells from human and murine heart. Circulation Research 95 911-921.
Montminy M 1997 Transcriptional regulation by cyclic AMP. Annual Review of Biochemistry 66 807-822.

Noble M, Smith J, Power J \& Mayer-Proschel M 2003 Redox state as a central modulator of precursor cell function. Annals of the New York Academy of Sciences 991 251-271.

Nunes MC, Roy NS, Keyoung HM, Goodman RR, McKhann II, Jang L, Kang J, Nedergaard M \& Goldman SA 2003 Identification and isolation of multipotential neural progenitor cells from the subcortical white matter of the adult human brain. Nature Medicine 9 439-447.

Pain D, Chirn GW, Strassel C \& Keup DM 2005 Multiple retropseudogenes from pluripotent cell-specific gene expression indicates a potential signature for novel gene identification. Journal of Biological Chemistry 280 6265-6268.

Pluchino S, Quattrini A, Brambilla E, Gritti A, Salani G, Dina G, Galli R, Del Carro U, Amadio S, Bergami A et al. 2003 Injection of adult neurosphere induces recovery in a chronic model of multiple sclerosis. Nature $\mathbf{4 2 2}$ 688-694.

Pohlenz J, Duprez L, Weiss RE, Vassart G, Refetoff S \& Costagliola S 2000 Failure of membrane targeting causes the functional defect of two mutant sodium iodide symporters. Journal of Clinical Endocrinology and Metabolism 85 2366-2369.

Puglisi MA, Guilani L \& Fierabracci A 2008 Identification and characterisation of a novel expandible adult stem/progenitor cell population in the human exocrine pancreas. Journal of Endocrinological Investigation 31 563-572 (in press).

Reis-Filho JS, Preto A, Soares P, Ricardo S, Cameselle-Teijeiro J \& SobrinhoSimoes M 2003 p63 expression in solid cell nests of the thyroid: further evidence for a stem cell origin. Modern Pathology 16 43-48.

Ruf J, Toubert ME, Czarnocka B, Durand-Gorde JM, Ferrand M \& Carayon P 1989 Relationship between immunological and biochemical properties of human thyroid peroxidase. Endocrinology 125 1211-1218.

Shih CC, Weng Y, Mamelak A, LeBon T, Hu MC \& Forman SJ 2001 Identification of a candidate human neurohematopoietic stem-cell population. Blood 98 2412-2422.

Srivatsa B, Srivatsa S, Johnson KL, Samura O, Lee SL \& Bianchi DW 2001 Microchimerism of presumed fetal origin in thyroid specimens from women: a case-control study. Lancet 358 2034-2038.

Studer H, Peter HJ \& Gerber H 1989 Natural heterogeneity of thyroid cells: the basis for understanding thyroid function and nodular goiter growth. Endocrine Reviews 10 125-135.

Teng YD, Lavik EB, Qu X, Park KI, Ourednik J, Zurakowski D, Lancer R \& Snyder Y 2002 Functional recovery following traumatic spinal cord injury mediated by a unique polymer scaffold seeded with neural stem cells. PNAS 99 3024-3029.

Thomas T, Nowka K, Lan L \& Derwahl M 2006 Expression of endoderm stem cell markers: evidence for the presence of adult stem cells in human thyroid glands. Thyroid 16 537-544.

Thomas D, Friedman S \& Lin R-Y 2008 Thyroid stem cells: lessons from normal development and thyroid cancer. Endocrine-Related Cancer 15 51-58.

Toda S, Koike N \& Sugihara H 2001 Cellular integration of thyrocytes and thyroid folliculogenesis: a perspective for thyroid tissue regeneration and engineering. Endocrine Journal 48 407-425.

Toda S, Watanabe K, Yokoi F, Matsumura S, Suzuki K, Ootani A, Aoki S, Koike N \& Sugihara H 2002 A new organotypic culture of thyroid tissue maintains three-dimensional follicles with C cells for a long term. Biochemical and Biophysical Research Communications 294 906-911.

Toda S, Aoki S, Suzuki K, Koike E, Ootani A, Watanabe K, Koike W \& Sugihara H 2003 Thyrocytes, but not C cells, actively undergo growth and folliculogenesis at the periphery of thyroid tissue fragments in three-dimensional collagen gel culture. Cell and Tissue Research 312 281-289.

Tonacchera M, Viacava P, Fanelli G, Agretti P, De Marco G, De Servi M, Di Cosmo C, Chiovato L, Pinchera A \& Vitti P 2004 The sodium-iodide symporter protein is always present at a low expression and confined to the cell membrane in nonfunctioning nonadenomatous nodules of toxic nodular goitre. Clinical Endocrinology 61 40-45. 
De Tullio R, Averna M, Salamino F, Pontremoli S \& Melloni F 2000 Differential degradation of calpastatin by mu- and m-calpain in $\mathrm{Ca}(2+)$ enriched human neuroblastoma LAN-5 cells. FEBS Letters 475 17-21.

Uchida N, Buck DW, He D, Reitsma MJ, Masek M, Phan TV, Tsukamoto AS, Gage FH \& Weissman IL 2000 Direct isolation of human central nervous system stem cells. PNAS 97 14720-14725.

Vescovi AL, Reynolds BA, Fraser DD \& Weiss S 1993 bFGF regulates the proliferative fate of unipotent (neuronal) and bipotent (neuronal/astroglial) EGF-generated CNS progenitor cells. Neuron 11 951-966.

Wagers AJ \& Weissman IL 2004 Plasticity of adult stem cells. Cell 116 639-648.

Weissman IL 2000 Stem cells: units of development, units of regeneration and units in evolution. Cell 100 157-168.

Yu Y, Flint A, Dvorin EL \& Bischoff J 2002 AC133-2, a novel isoform of human AC133 stem cell antigen. Journal of Biological Chemistry 277 20711-20716.
Zuk PA, Zhu M, Ashjian P, De Ugarte DA, Huang JI, Mizuno H, Alfonso ZC, Fraser JK, Benhaim P \& Hedrick MH 2002 Human adipose tissue is a source of multipotent stem cells. Molecular Biology of the Cell 13 4279-4295.

Zulewski H, Abraham EJ, Gerlach MJ, Daniel PB, Moritz W, Müller B, Vallejo M, Thomas MK \& Habener JF 2001 Multipotential nestin-positive stem cells isolated from adult pancreatic islets differentiate ex vivo into pancreatic endocrine, exocrine, and hepatic phenotypes. Diabetes $\mathbf{5 0}$ $521-533$.

Received in final form 10 May 2008

Accepted 11 June 2008

Made available online as an Accepted Preprint 11 June 2008 